\title{
REVIEWS
}

Check for updates

\section{A framework for developing sex-specific engineered heart models}

\author{
Roberta Lock', Hadel Al Asafen 2,3, Sharon Fleischer', Manuel Tamargo ${ }^{1}$, Yimu Zhao', \\ Milica Radisic (10 ${ }^{2,3}$ and Gordana Vunjak-Novakovic (10) ${ }^{1,4 凶}$
}

\begin{abstract}
The convergence of tissue engineering and patient-specific stem cell biology has enabled the engineering of in vitro tissue models that allow the study of patient-tailored treatment modalities. However, sex-related disparities in health and disease, from systemic hormonal influences to cellular-level differences, are often overlooked in stem cell biology, tissue engineering and preclinical screening. The cardiovascular system, in particular, shows considerable sex-related differences, which need to be considered in cardiac tissue engineering. In this Review, we analyse sex-related properties of the heart muscle in the context of health and disease, and discuss a framework for including sex-based differences in human cardiac tissue engineering. We highlight how sex-based features can be implemented at the cellular and tissue levels, and how sex-specific cardiac models could advance the study of cardiovascular diseases. Finally, we define design criteria for sex-specific cardiac tissue engineering and provide an outlook to future research possibilities beyond the cardiovascular system.
\end{abstract}

Cardiovascular disease is a leading cause of death around the world ${ }^{1}$. Notably, major differences between male and female patients exist in nearly every aspect of cardiovascular disease, from epidemiology to outcome $^{2}$. Investigating the influence of sex on cardiac (patho)physiology could lead to better mechanistic understanding of diseases, increase efficacy and safety of drug development, and allow the design of targeted treatments for both sexes. Unfortunately, although differences between the sexes have been acknowledged, sex is often overlooked as a variable in scientific research ${ }^{3-5}$. Historically, male patients have dominated clinical and preclinical trials, owing to the belief that sex-based differences are only relevant for the reproductive system and to reduce variability in experiments caused by hormone fluctuations in women. However, sex differences are increasingly considered in scientific studies ${ }^{6,7}$.

The observed clinical disparities are a result of the amalgamation of differences owing to sex and gender, which are analytically distinct but inextricably connected. 'Sex' refers to biologically determined attributes (chromosomes, sex organs, endogenous hormone profiles), whereas 'gender' refers to characteristics that are socially constructed ${ }^{7,8}$. Neither sex nor gender are binary, and different sexes exist (for example, Turner syndrome (X), Klinefelter syndrome (XXY) and XYY or XXXY syndromes); however, in this Review, we compare only between male (XY) and female (XX) biological sexes, which are referred to here as men and women, respectively. Although most differences are attributed to sex-specific hormones, they are only one of several contributing factors (FIG. 1). This is exemplified by gonadectomy studies in animal models, which have shown that female-specific, angiotensin-induced vasodilation is maintained regardless of hormone status ${ }^{9,10}$. In humans, the impact of societal stressors associated with gender are considerable. Recent studies on the association between cardiovascular risk factors and transgender status support the idea that, although important, sex hormone status is not entirely responsible for the differences between men and women. Interestingly, transgender women receiving exogenous oestrogen as part of their treatment experience increased risk of myocardial infarction and ischaemic stroke compared with cisgender women ${ }^{11,12}$. By contrast, there is no convincing evidence that treatment with testosterone in transgender men increases the risk of cardiovascular disease compared with cisgender men, but it leads to a higher rate of myocardial infarction compared with cisgender women. As multiple sex-related factors are involved in regulating cardiac function, it is important to understand their individual and synergistic roles. To this end, tissue engineering and stem cell biology provide a unique opportunity to parse out sex-based and gender-based differences and investigate the mechanisms contributing to sexual dimorphisms in humans. The incorporation of sex-specificity into tissue-engineered constructs will increase our understanding of the role of sex in health and disease. 


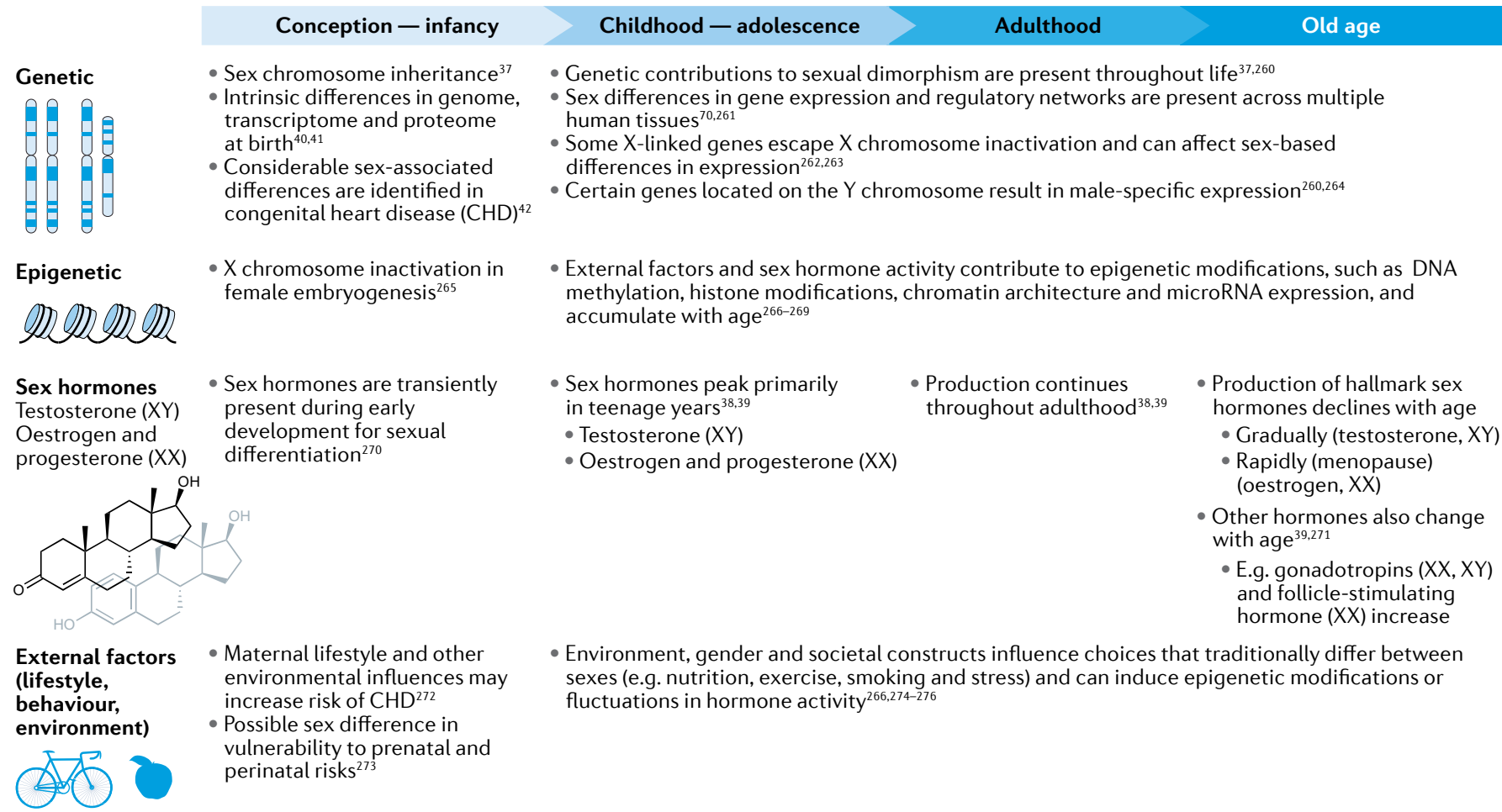

Fig. 1 | Factors contributing to sex-based cardiac differences. Differences between male and female cardiac physiology in humans arise from genetic, epigenetic, sex hormone, environmental, behavioural and lifestyle factors, which interact and change throughout life and are not easy to delineate ${ }^{260-276}$.

\section{Engineered cardiac models}

In traditional cardiac tissue engineering approaches (FIG. 2), cardiomyocytes are cultured into large and elongated constructs expressing cardiac genes associated with contraction and calcium handling, displaying orderly ultrastructure and producing forces characteristic of a mature phenotype $\mathrm{e}^{13-16}$. The addition of supporting stromal cells, such as cardiac fibroblasts and endothelial cells, can further increase the structural and functional properties of the tissue ${ }^{17}$. Subjecting engineered cardiac tissue to mechanical stress by stretching tissue anchored to pillars or wires improves cellular alignment and sarcomeric organization, and increases contractile force and expression of cardiac markers, as compared with statically grown tissue ${ }^{18-20}$. Further maturation can be achieved by subjecting the tissue to electrical pacing ${ }^{19,21-25}$. Electrical stimulation increases maturation efficacy if the stimulation starts at a low frequency and is gradually increased over time by applying an 'intensity training' regimen ${ }^{26,27}$, resulting in tissues with adult-like gene expression, sarcomeric organization with networks of t-tubules, high mitochondrial density and more physiological contractile behaviour and drug responses $^{26}$, as compared with non-stimulated tissue.

Advances in cardiomyocyte differentiation protocols have enabled differentiation into atrial and ventricular cardiomyocytes for the fabrication of chamber-specific tissue, which produces distinct electrophysiological and drug responses between the atrial-specific versus ventricular-specific tissues ${ }^{27-29}$. Moreover, 3D bioprinting allows fabrication of scaled models of the heart ventricles, incorporation of vasculature and even reproduction of patient-specific anatomical structures ${ }^{30-33}$. Furthermore, organ-organ interactions are being explored; for example, cardiac tissue models can be cultured with other tissues (such as liver, kidneys and lung) ${ }^{34-36}$. Tissue engineering approaches have more physiological relevance than traditional monolayer cultures, and mature engineered cardiac tissues provide versatile platforms for cardiac research (FIG. 3), which can be tailored to study specific biological questions.

Although much progress has been made in cardiac tissue engineering, the complete recapitulation of the physiology of the adult human heart has yet to be achieved. The physiological relevance of cardiac models can be further improved by tailoring their design to represent specific populations, such as men and women. Cardiac tissues are often modified to model specific diseases; however, to the best of our knowledge, a systematic investigation, comparison and modelling of male and female engineered cardiac tissues remains elusive thus far.

\section{Modelling sex-based differences Cardiac physiology}

Here, we briefly review factors contributing to sexual dimorphism in cardiac muscle, identify quantifiable differences that can be recapitulated in cardiac tissue models and discuss engineering tools. Differences in male and female cardiac physiology in humans arise from combined effects of genetics, epigenetics, sex hormones, environmental, behavioural and lifestyle factors (FIG. 1). Genetics contribute to sex differences largely via the sex chromosomes, which are determined 
(1)<smiles>CC12CC3CC(CC(C3)C1)C2</smiles>

(2)

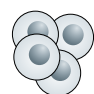

(4)

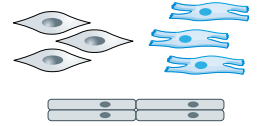

(5)

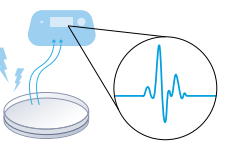

(6)

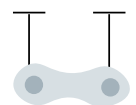

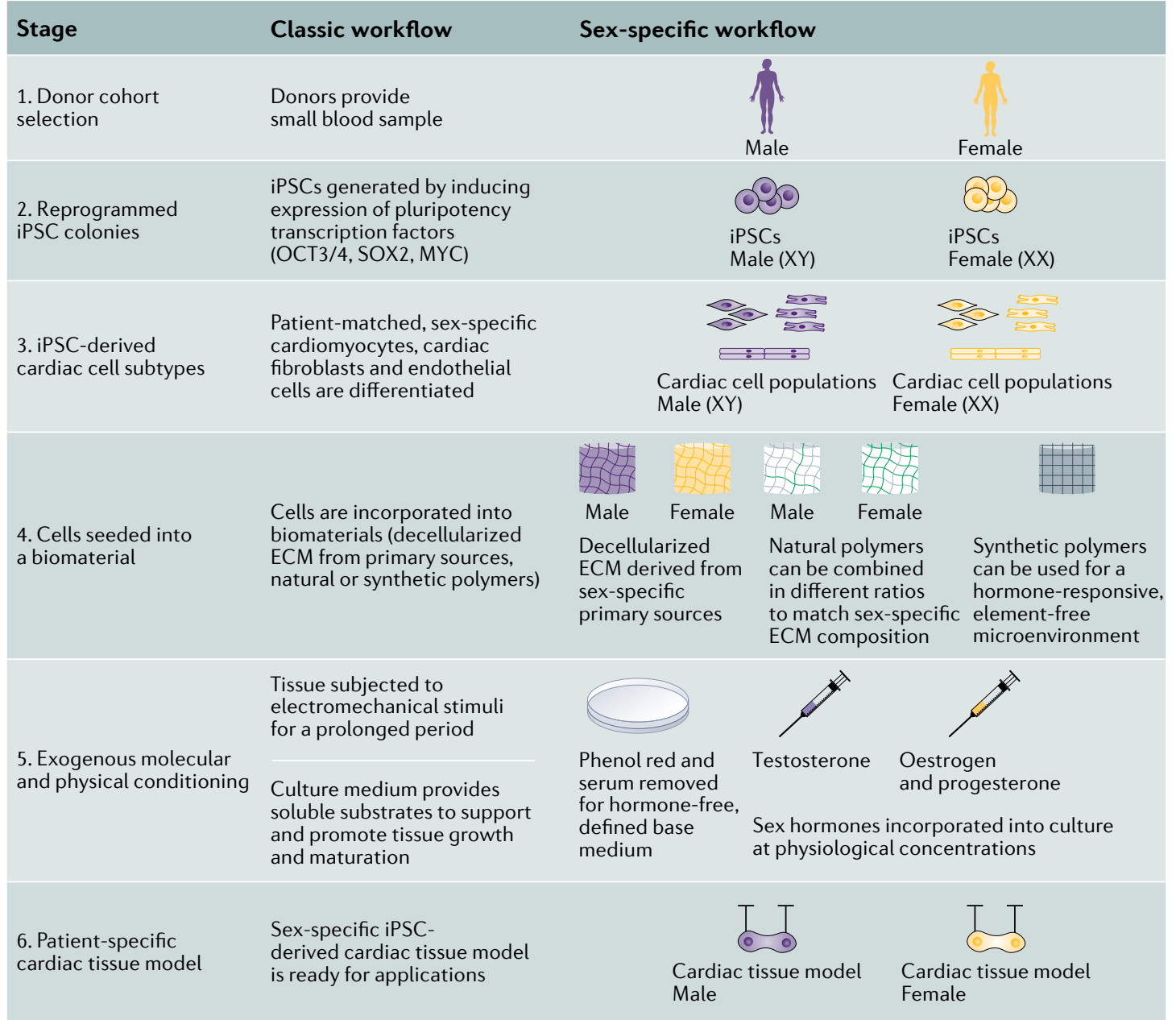

Fig. 2 | Workflow for creating engineered cardiac models. Engineered cardiac tissue models are 3D constructs that are grown using cells, biomaterials and exogenous factors to recapitulate patient-specific cardiac phenotypes in vitro. Regardless of the specific tissue design, a common workflow can be outlined and each step can be designed in a sex-specific way. Human induced pluripotent stem cells (iPSCs) are first derived from donors, differentiated into cardiomyocytes and supporting cells, and seeded into a biomaterial. The resulting engineered tissue is cultured in an appropriate culture medium and subjected to electromechanical conditioning. Finally, the cardiac tissue is matured to recapitulate the phenotype of the donor. ECM, extracellular matrix.

at conception ${ }^{37}$. In general, sex-specific differences can be related to the imbalance in gene dosage caused by inefficient $\mathrm{X}$ chromosome inactivation in women and the genes located in the male-specific region of the $\mathrm{Y}$ chromosome. Epigenetic modifications, such as DNA methylation, histone modification and chromatin remodelling, begin during development and accumulate with age. Production of sex hormones increases and peaks during adolescence ${ }^{38}$, continues throughout adulthood and begins to decline around the age of 50 years. In men, testosterone levels decrease gradually, whereas in women, oestrogen and progesterone levels fall rapidly during menopause ${ }^{39}$. Environmental, social and behavioural influences include exercise and diet, which indirectly impact sex differences by modifying sex hormone activity and epigenetics. For the heart, the resulting sex differences are evident at the molecular level in the transcriptome and proteome at birth, and are pronounced during congenital heart disease ${ }^{40-42}$. After the onset of puberty, sex differences become more evident and change with age throughout life. The vast majority of studies investigating effects of sex on cardiac physiology are conducted within the context of disease. However, to truly understand the differences in abnormal conditions, the differences in normal physiology need to be properly defined (TABLE 1).

Cells. In a healthy heart, the cellular distribution is generally similar in women and men, with a slightly higher percentage of ventricular cardiomyocytes in women $(56 \% \pm 9 \%)$ compared with men $(47 \% \pm 11 \%)^{43}$. In mice, amongst the non-myocytes, more endothelial cells were reported in male than in female cardiac tissue, whereas the proportion of resident stromal cells (fibroblasts, smooth muscle cells, Schwann cells and pericytes) is higher in female tissue ${ }^{44}$. Interestingly, the study also suggests that cardiac cellularity is at least partially regulated by sex hormones, because after gonadectomy, previously distinct cellular profiles of male and female hearts become similar. 
In tissue engineering, the consistency of cell sources is vital for the creation of a robust tissue model. Primary animal cells (primary human cells are highly limited in supply) or cells differentiated from human stem cells are most commonly used. Induced pluripotent stem cells (iPSCs) can be derived from a small blood sample and differentiated into the types of cell comprising the heart muscle (ventricular, atrial and sinoatrial node cardiomyocytes, cardiac fibroblasts, endothelial cells, immune cells $)^{45-48}$. Therefore, cell lines can be generated from male and female patients, allowing the creation of sex-specific cells. Sex-based differences have been studied in monolayers of iPSC-derived cardiomyocytes ${ }^{49-52}$; however, the immature state of these cells limits their capability to recapitulate human (patho)physiology and sex-based differences in tissue function ${ }^{53,54}$, which can be addressed by developing mature cardiac tissues, adding stromal cells and optimizing media formulations.

Extracellular matrix. Studies of sex differences in extracellular matrix (ECM) composition in myocardial tissue remain limited. Analysis of healthy human left ventricular tissue revealed sex-specific regulation of several ECM proteins ${ }^{55}$. Tissues from young women contain less collagen type I, III and IV in comparison with men, whereas this is reversed with age. The expression of transforming growth factor- $\beta$ (TGF $\beta$ ) and tissue inhibitors of metalloproteinases (TIMPs), both involved in cardiac remodelling processes, also differs. At young age, women have less SMAD2 and SMAD3, which are proteins that a Pillar-based model

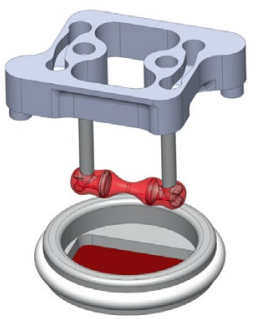

b Biowire II

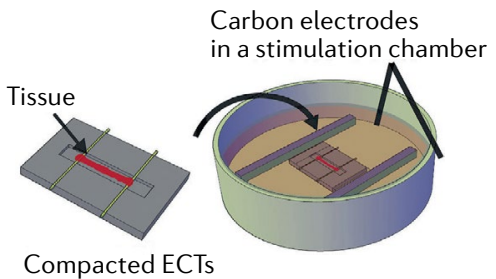

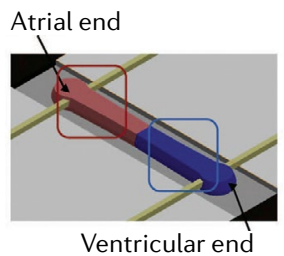

c I-Wire Heart-on-a-chip

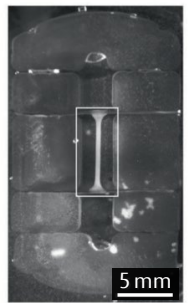

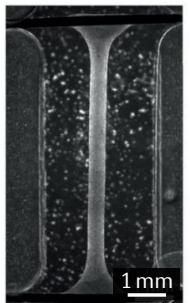

d Ring-shaped, chamber-specific heart tissues

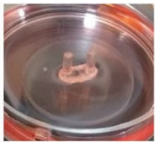

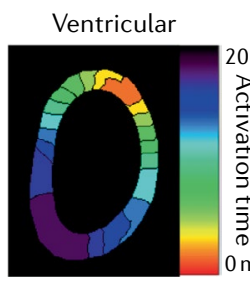

Atrial

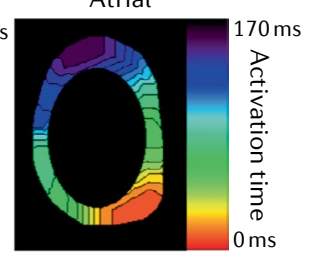

e 3D printing of personalized thick and perfusable cardiac patches and hearts

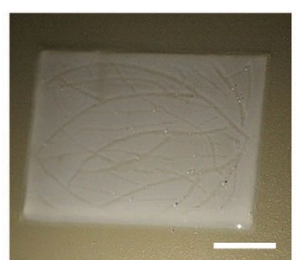

Personalized cardiac patch

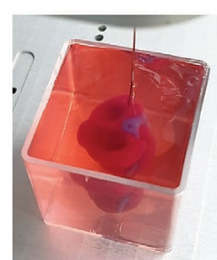

Bioprinted heart

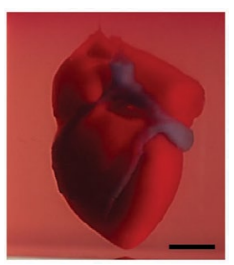

\section{f Tissue-engineered scale models of the human left ventricle}

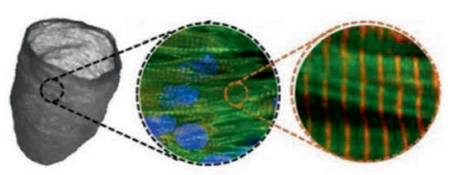

Cell culture in scaffold Ventricle scale model

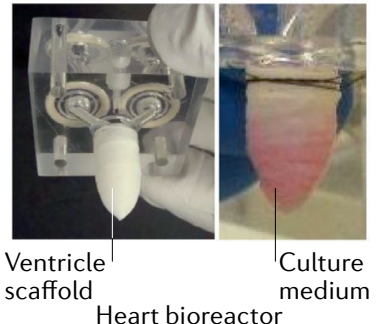

Heart bioreactor
Fig. 3 | Engineered cardiac tissue models. a | Human induced pluripotent stem cell-derived cardiomyocytes and supporting cardiac fibroblasts encapsulated in a fibrin hydrogel can be subjected to tension between two elastic pillars ${ }^{26} \cdot \mathbf{b} \mid$ The Biowire Il platform allows the creation of electrophysiologically distinct atrial and ventricular tissues attached to two polymer wires. c| The I-Wire platform combines neonatal ventricular rat cells in a fibrinogen-Matrigel-thrombin hydrogel into a polydimethylsiloxane mould with a channel for the 3D tissue and titanium wires on either side. d) Chamber-specific heart tissues can be created from ventricular and atrial human pluripotent stem cell-derived cardiomyocytes embedded in a collagen hydrogel. e | Using a hydrogel derived from human omentum and patient-specific cardiomyocytes and endothelial cells, personalized bioinks can be created to bioprint vascularized patches. $\mathbf{f} \mid$ Tissue-engineered ventricles are prepared from seeding ellipsoidal ventricle scaffolds with g 3D-bioprinted collagen to engineer components of the human heart

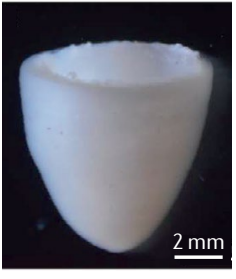

Cardiac ventricle

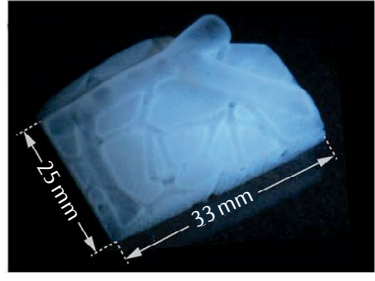

Vascular network

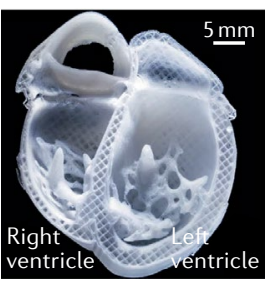

Organ scale cardiomyocytes. Their contractile properties are evaluated by pressurevolume catheterization in the heart bioreactor. $\mathbf{g}$ | Collagen can be 3D-printed using freeform reversible embedding of suspended hydrogels to generate parts of the human heart at different scales. The selection of the most appropriate model depends on the specific question and the functional outcomes being measured (for example, tissues anchored to pillars are especially useful for studies requiring measurements of force generation). Ultimately, the choice should be made at the user's discretion. ECT, engineered cardiac tissue. Panel $\mathbf{b}$ reprinted with permission from REF. ${ }^{27}$, Elsevier. Panel $\mathbf{c}$ reprinted with permission from REF. ${ }^{21}$, Elsevier. Panel d reprinted from REF. ${ }^{28}$, CC BY 4.0 (https://creativecommons.org/licenses/ by/4.0/). Panel e reprinted from REF. ${ }^{30}$, CC BY 4.0 (https://creativecommons. org/licenses/by/4.0/). Panel f reprinted from REF. ${ }^{31}$, Springer Nature Limited. Panel $\mathbf{g}$ reprinted with permission from REF. ${ }^{32}$, AAAS. 
Table 1 | Differences between male and female hearts

\begin{tabular}{|c|c|c|c|c|c|}
\hline \multicolumn{2}{|l|}{ Parameters } & \multirow{2}{*}{$\begin{array}{l}\text { Females } \\
56 \pm 9 \%\end{array}$} & \multirow{2}{*}{$\begin{array}{l}\text { Males } \\
47 \pm 11 \%\end{array}$} & \multirow{2}{*}{$\begin{array}{l}\text { Model } \\
\text { Human heart } \\
\text { transmural sample }\end{array}$} & \multirow{2}{*}{ Refs } \\
\hline Cells & $\begin{array}{l}\text { Proportion of ventricular } \\
\text { CMs }\end{array}$ & & & & \\
\hline & \multirow[t]{2}{*}{$\begin{array}{l}\text { Proportion of } \\
\text { non-myocyte cells }\end{array}$} & $\begin{array}{l}\text { Lower proportion of } \\
\text { endothelial cells }\end{array}$ & $\begin{array}{l}\text { Higher proportion of } \\
\text { endothelial cells }\end{array}$ & \multirow[t]{2}{*}{ Mouse } & \multirow[t]{2}{*}{${ }^{44}$} \\
\hline & & $\begin{array}{l}\text { Higher proportion of resident } \\
\text { mesenchymal cells }\end{array}$ & $\begin{array}{l}\text { Lower proportion of resident } \\
\text { mesenchymal cells }\end{array}$ & & \\
\hline & $\begin{array}{l}\text { Ventricular myocyte loss } \\
\text { through apoptosis }\end{array}$ & $\begin{array}{l}\text { No ventricular myocyte loss } \\
\text { with ageing }\end{array}$ & $\begin{array}{l}\text { Ventricular myocyte loss } \\
\text { with ageing }\end{array}$ & $\begin{array}{l}\text { Rat and monkey } \\
\text { hearts }\end{array}$ & 108,229 \\
\hline \multirow[t]{5}{*}{ Extracellular matrix } & Collagens & $\begin{array}{l}\text { Lower collagen I, collagen III } \\
\text { and collagen IV at young age } \\
\text { (higher at old age) }\end{array}$ & $\begin{array}{l}\text { Higher collagen I, } \\
\text { collagen III and collagen IV } \\
\text { at young age (lower at } \\
\text { old age) }\end{array}$ & \multirow[t]{3}{*}{$\begin{array}{l}\text { Healthy human } \\
\text { left ventricular } \\
\text { myocardial samples }\end{array}$} & \multirow[t]{3}{*}{55} \\
\hline & TIMPs & $\begin{array}{l}\text { Lower TIMP1 and TIMP3 at } \\
\text { young age (higher at old age) }\end{array}$ & $\begin{array}{l}\text { Higher TIMP1 and TIMP3 } \\
\text { at young age (lower at } \\
\text { old age) }\end{array}$ & & \\
\hline & \multirow[t]{2}{*}{ TGF $\beta$-associated factors } & $\begin{array}{l}\text { Lower SMAD2 and SMAD3 at } \\
\text { young age (higher at old age) }\end{array}$ & $\begin{array}{l}\text { Higher SMAD2 and SMAD3 } \\
\text { at young age (lower at old } \\
\text { age) }\end{array}$ & & \\
\hline & & $\begin{array}{l}\text { Increased expression of TGF } \beta \\
\text { receptor } 1 \text { with age }\end{array}$ & $\begin{array}{l}\text { No change in expression } \\
\text { of TGF } \beta \text { receptor } 1 \\
\text { with age }\end{array}$ & \multirow[t]{2}{*}{ Mouse } & \multirow[t]{2}{*}{56} \\
\hline & $\begin{array}{l}\text { Collagen } \\
\text { metabolism-associated } \\
\text { factors }\end{array}$ & $\begin{array}{l}\text { Higher periostin at young and } \\
\text { old age }\end{array}$ & $\begin{array}{l}\text { Lower periostin at young } \\
\text { and old age }\end{array}$ & & \\
\hline \multirow{3}{*}{ Gene expression } & $\begin{array}{l}\text { SCN10A (associated } \\
\text { with hypertrophic } \\
\text { cardiomyopathy) }\end{array}$ & \multirow[t]{2}{*}{ Higher expression } & \multirow[t]{2}{*}{ Lower expression } & \multirow[t]{2}{*}{ Human heart tissue } & \multirow[t]{2}{*}{71} \\
\hline & $\begin{array}{l}\text { KCNE1 (associated with } \\
\text { long QT syndrome) }\end{array}$ & & & & \\
\hline & $\begin{array}{l}\text { NPPB (associated with } \\
\text { cardiomyopathy) }\end{array}$ & Higher expression & Lower expression & Human heart tissue & 69 \\
\hline \multirow[t]{5}{*}{ Contractility } & Contraction frequency & $78-82$ beats $\mathrm{min}^{-1}$ & $70-72$ beats $\mathrm{min}^{-1}$ & $\begin{array}{l}\text { Healthy human } \\
\text { subjects }\end{array}$ & 230 \\
\hline & \multirow[t]{2}{*}{ Ejection fraction } & \multirow{2}{*}{$\begin{array}{l}\text { Higher LVEF } \\
\text { (median (25th, } 75 \text { th percentile)) } \\
75 \%(70 \%, 79 \%)\end{array}$} & $\begin{array}{l}\text { Lower LVEF (median (25th, } \\
\text { 75th percentile)) }\end{array}$ & \multirow[t]{2}{*}{$\begin{array}{l}\text { Healthy human } \\
\text { subjects }\end{array}$} & \multirow[t]{2}{*}{77} \\
\hline & & & $70 \%(65 \%, 75 \%)$ & & \\
\hline & \multirow[t]{2}{*}{ Fractional cell shortening } & Lower & Higher & \multirow[t]{2}{*}{ Isolated rat myocytes } & \multirow[t]{2}{*}{78,79} \\
\hline & & No change with ageing & Decreases with ageing & & \\
\hline \multirow[t]{3}{*}{ Electrophysiology } & QT interval & $470 \mathrm{~ms}$ & $450 \mathrm{~ms}$ & Human patients & 86 \\
\hline & APD90 & $870 \mathrm{~ms}$ & $670 \mathrm{~ms}$ & $\begin{array}{l}\text { Human ventricular } \\
\text { myocytes isolated } \\
\text { from failing human } \\
\text { hearts }\end{array}$ & 90 \\
\hline & $\begin{array}{l}\text { Potassium repolarizing } \\
\text { currents }\end{array}$ & Smaller & Larger & $\begin{array}{l}\text { Isolated rabbit } \\
\text { myocytes }\end{array}$ & 82 \\
\hline
\end{tabular}


Table 1 (cont.) | Differences between male and female hearts

\begin{tabular}{|c|c|c|c|c|c|}
\hline Parameters & & Females & Males & Model & Refs \\
\hline \multirow[t]{4}{*}{ Calcium handling } & $\begin{array}{l}\text { lon channels (Cav1.2a, } \\
\text { NCX1) }\end{array}$ & Higher expression & Lower expression & $\begin{array}{l}\text { Cardiomyocytes } \\
\text { derived from male } \\
\text { and female human } \\
\text { iPSCs }\end{array}$ & 49 \\
\hline & Calcium transients & Smaller & Larger & $\begin{array}{l}\text { Rat myocytes, mouse } \\
\text { myocytes }\end{array}$ & $79,94-96,231$ \\
\hline & \multirow[t]{2}{*}{$\begin{array}{l}\beta \text {-Adrenergic stimulation } \\
\text { response }\end{array}$} & $\begin{array}{l}\text { Reduced response (compared } \\
\text { with males) }\end{array}$ & - & \multirow[t]{2}{*}{$\begin{array}{l}\text { Rat myocytes, mouse } \\
\text { myocytes }\end{array}$} & \multirow[t]{2}{*}{$95-97$} \\
\hline & & Decreased changes to APD & Increased changes to APD & & \\
\hline \multirow[t]{5}{*}{ Energy metabolism } & \multirow{3}{*}{$\begin{array}{l}\text { Cardiac mitochondria } \\
\text { morphology }\end{array}$} & Greater number & Fewer number & \multirow[t]{3}{*}{ Mouse } & \multirow[t]{3}{*}{100} \\
\hline & & Larger area & Smaller area & & \\
\hline & & Elongated morphology & $\begin{array}{l}\text { Circular, fragmented } \\
\text { morphology }\end{array}$ & & \\
\hline & \multirow{2}{*}{$\begin{array}{l}\text { Mitochondrial transition } \\
\text { pore opening }\end{array}$} & Lower calcium sensitivity & Higher calcium sensitivity & \multirow[t]{2}{*}{ Rat } & \multirow[t]{2}{*}{$105-107$} \\
\hline & & $\begin{array}{l}\text { Higher myocyte calcium } \\
\text { retention capacity }\end{array}$ & $\begin{array}{l}\text { Lower myocyte calcium } \\
\text { retention capacity }\end{array}$ & & \\
\hline
\end{tabular}

function as the main signal transducers for TGF $\beta$ receptor signalling, as well as less TIMP1 and TIMP3 than men. In mice, age-dependent increases in TGF $\beta$ receptor 1 (TGF $\beta R 1)$ and SMAD2/3 have been reported in females but not in males ${ }^{56}$. Thus, there is evidence for sex-based differences in cardiac ECM composition and remodelling throughout life; however, underlying regulatory mechanisms and impact on disease pathology remain to be explored.

Cardiac tissue engineering requires the incorporation of cells into a biomaterial, which acts as the ECM and provides cells with physical and biochemical cues that affect cellular signalling, organogenesis, tissue homeostasis and disease processes. Initially, cardiomyocytes seeded within biomaterials are round and lack cell-cell interaction. Biomaterials, such as decellularized ECM from primary sources, natural polymers, such as fibrin and collagen, and synthetic polymers, such as polyethylene glycol ${ }^{57}$, can guide cardiac cell spreading and elongation, and enable the establishment of cell-cell interactions to form an electrically coupled tissue that generates strong contraction forces. These biomaterials can be fabricated into hydrogels, macroporous and electrospun scaffolds. Biomaterials can also be designed to mimic the cardiac ECM; for example, electrospun fibre scaffolds with patterned biochemical cues and microchannels and nanochannels can control cell directionality and elongation ${ }^{58,59}$, enabling the formation of aligned tissue that supports anisotropic electrical propagation. Cardiomyocytes are also highly sensitive to matrix stiffness ${ }^{60}$. The mechanical properties of biomaterials can be adjusted by varying polymer and crosslinker concentrations, and the mechanical anisotropy of the heart can be recapitulated by controlling macroscopic biomaterial geometry ${ }^{61,62}$. As the cardiac ECM also serves as a depot for regulatory molecules, biomaterials can be functionalized with these molecules to support cardiomyocyte survival and maturation, as well as vascularization $^{63}$. Finally, the incorporation of conductive materials, such as gold nanoparticles, graphene and carbon nanotubes, can improve the electrical properties of cardiac tissues ${ }^{64-66}$.

Overall, the type of biomaterial needs to be chosen and designed based on the specific biological question. Although sex-specificity of ECM in cardiac engineering has not yet been studied, it has been investigated in other fields, such as breast cancer tissue models, in which, for example, oestrogen receptor activity must be considered.

Gene expression. Genome-wide studies suggest sexspecific genetic architectures of human tissues. RNA sequencing of rodent hearts revealed substantial sexual dimorphism of cardiac tissue, identifying approximately 600 genes with sexually dimorphic expression ${ }^{67,68}$. RNA sequencing and microarray datasets of human tissues revealed slightly fewer sexually differentiated genes (average of 300-400 genes), with the heart being one of the most sexually dimorphic organs in the body, following the reproductive organs, breast tissue and the brain ${ }^{69-71}$. Single-cell RNA sequencing further showed sexual dimorphism in gene expression in all cell populations within the heart, with the most sexually dimorphic genes in cardiac fibroblasts ${ }^{72}$. In particular, pathways involved in glucose and lipid metabolism, as well as contraction, have been implicated in differential gene expression in the heart. For example, expression 
of myosin light chain 4 (MYL4), which increases force production in cardiomyocytes, was found to be higher in men than in women, correlating to stronger cellular contraction in $\operatorname{men}^{73}$. Several genes linked to cardiomyopathy, most notably sodium voltage-gated channel a-subunit 10 (SCN10A), natriuretic peptide B (NPPB) and potassium voltage-gated channel subfamily $\mathrm{E}$ regulatory subunit 1 (KCNE1), are more highly expressed in women than in men $^{69,71}$. Unsurprisingly, the genes with the highest sex-based differential expression in human cardiac tissue are located on the sex chromosomes. However, about two-thirds of sex-biased genes are not directly influenced by sex hormones or under the control of sex hormones or sex chromosomes ${ }^{71}$. Although the mechanisms that underpin these differences are not yet fully understood, the identification of sex-biased genes provides a foundation for investigating sexually dimorphic tissue, as well as a tool and resource for benchmarking sex-specificity of engineered cardiac tissues.

Various tools are available to study differences in gene expression in engineered cardiac tissues. Sexually dimorphic gene expression has mainly been investigated by high-throughput sequencing technologies, such as RNA sequencing, enabling transcriptome-wide analysis of differential gene expression ${ }^{74}$. This technology can also be used with in vitro tissue models, in which gene expression can be further interrogated using gene editing techniques ${ }^{75}$. For example, CRISPR technology can be used to modulate the expression of a specific gene or pathway of interest to evaluate its impact on tissue function. Additionally, reporter lines can be generated to investigate the activity of specific genes in response to different conditions. Many reporter lines have been used in cardiac tissue engineering studies, such as ventricular-specific and atrial-specific gene expression reporters ${ }^{76}$. In sex-specific studies, reporter lines could be used to evaluate changes in cardiac tissue function in response to hormone treatment or activity of particular hormone receptors. Fluorescent reporters can further provide functional readouts; for example, genetically encoded calcium indicators can be used for evaluation of calcium handling, and markers can be generated for apoptosis, reactive oxygen species (ROS) generation and mitochondrial function ${ }^{76}$.

Contractility. The main function of cardiomyocytes is coordinated contraction to allow the heart muscle to pump blood. Macroscopically, there are very few differences in contractility between healthy men and women. For example, the slower beat rate of male hearts (7072 beats per minute) as compared with female hearts (78-82 beats per minute) can be accounted for by the overall size of the heart, which is proportional to body size and typically larger in men. At rest, women have higher left ventricular ejection fraction (LVEF) than men, independent of the left ventricular volume, reflecting a higher stroke volume ${ }^{77}$. In animal models, however, contractions in isolated rat cardiomyocytes are weaker in female cells than in male cells ${ }^{78}$. This difference changes with age, as male rats show decreased fractional cell shortening with ageing, whereas female rats show no such decrease $\mathrm{e}^{79}$. A trend in both animals and humans is the lower ability of female hearts to respond to stress than male hearts. During exercise, men have a greater increase in ejection fraction than women ${ }^{77}$.

In vivo, the contractile function of the heart is evaluated by the ejection fraction, measured by echocardiography. In vitro, measurement of contractility depends on the model design. For isolated cardiomyocytes and cell monolayers, contractile function can be quantified through visual assessment of cellular fractional shortening ${ }^{80}$. Traction force microscopy can also be used to measure the forces a cardiomyocyte transmits to an underlying substrate during contraction. Contraction-relaxation kinetics can be further evaluated by high-speed video microscopy and motion vector analysis ${ }^{81}$. In tissues anchored by pillars (FIG. 3a), the amplitude and frequency of contraction can be measured by image analysis of pillar deflection ${ }^{26}$. For ring-shaped models (FIG. 3d), forces can be measured by progressively stretching tissues placed on hooks that are attached to a force transducer and a length controller ${ }^{28}$. In a $3 \mathrm{D}$ ventricle model (FIG. 3f), contractile force can be analysed by catheterizing the ventricle and by taking pressure and volume recordings ${ }^{31}$. The selection of the tissue model for studying sex-specific differences will depend on the physiological property that is investigated. For example, contractile behaviour can be studied using tissues on anchors (FIG.3a-d), whereas pumping capacity may be studied using the model of ventricles (FIG. 3f).

Electrophysiology. It has long been known that women have longer QT intervals - measurements taken from an electrocardiogram representing the time from ventricular depolarization to the end of ventricular repolarization and smaller potassium-repolarizing currents ${ }^{82}$ than men, leading to less stable human ether-à-go-go-related gene (hERG) potassium channels that contribute to the greater prevalence of drug-induced QT prolongation ${ }^{83}$. These differences emerge after the onset of puberty, when QT interval duration in men begins to shorten ${ }^{84,85}$. Electrocardiogram recordings show that QT values corrected for heart rate (QTc values) post-puberty are less than $450 \mathrm{~ms}$ for men and less than $470 \mathrm{~ms}$ for women ${ }^{86}$. Indeed, in clinical studies, more cardiac arrhythmias were observed in women than in men in the 15-50-year age group, when the sex difference in QT interval is greatest $^{87}$. In an orchiectomized male rabbit model as well as in isolated guinea pig cardiomyocytes, testosterone shortens the QT interval ${ }^{88,89}$, which has also been shown in a clinical study, demonstrating the association between physiological levels of sex hormones and QT interval duration in humans ${ }^{85}$. The same study found that testosterone levels are inversely correlated with the QT interval in men but not in postmenopausal women, suggesting that testosterone levels may explain the differences of QT intervals between men and women ${ }^{85}$. In human ventricular myocytes isolated from the failing hearts of female and male patients at the time of cardiac transplantation, the action potential duration at $90 \%$ repolarization (APD90) was $670 \mathrm{~ms}$ for male and $870 \mathrm{~ms}$ for female cells ${ }^{90}$. Although these APD90 values are much higher than the APD90 values in a healthy adult heart (200-400 ms), these measurements prove 
that men exhibit shorter APD90s than women, that APD90 values of female ventricular cardiomyocytes are $29 \%$ longer than those of men and, although QTc duration is age-dependent, that APD90 has little or no age-dependence ${ }^{86,90}$.

The patch clamp assay is the gold standard for analysing the electrophysiology of cardiomyocytes, allowing the study of ion currents directly from the cell ${ }^{81}$. To perform this assay, tissues must be dissociated into single cells by enzymes, followed by plating at low cell density. Dissociation removes the cells from their native environment and affects membrane proteins, thereby changing cell behaviour. Electrophysiological assessment of intact tissues would provide more accurate functional data. Electrophysiology can be studied in tissues using a calcium indicator or a voltage-sensitive dye, enabling evaluation of real-time changes in calcium flux and voltage by fluorescence microscopy. Hybrid tissues with built-in electronics further allow non-invasive monitoring of electrophysiological tissue properties in real time $^{91}$. Moreover, external electrical stimulation can be used to interrogate tissue function. For example, electrical impulse propagation rates can be determined using point stimulation and optical mapping techniques ${ }^{92}$.

Calcium handling. Male and female cardiac tissues show differences in ion channel composition, with higher expression of L-type voltage-dependent calcium channel a1C subunit (Cav1.2a) and sodium-calcium exchanger (NCX1) in women ${ }^{49,93}$. Upon oestrogen conditioning, L-type $\mathrm{Ca}^{2+}$ and sodium-calcium exchange currents are upregulated and their respective mRNA levels increase in female but not in male cardiomyocytes, suggesting a role for oestrogen in modulating the expression of these ion channels. In murine models, calcium transients, calcium sparks and excitation-contraction coupling gain differ between males and females ${ }^{79,94,95}$. Although data vary between different rodent studies, females are considered to have lower calcium operational status than males ${ }^{95,96}$. Differences in cyclic adenosine monophosphate (cAMP)-protein kinase A (PKA) signalling, which is responsible for sarcoplasmic reticulum calcium release, is at least partly responsible for these disparities between sexes. Oestrogen regulation of cAMP-PKA signalling is supported by an ovariectomy (OVX) study in mice, showing significant differences in intracellular cAMP and calcium transients in females and oestrogen-treated OVX females compared with males and OVX females ${ }^{94}$. Oestrogen regulation of CAMP-PKA activation may also be responsible for differences in the response to $\beta$-adrenergic stimulation. Female hearts have a reduced response to isoprenaline, with smaller changes in action potential duration compared with males in small animal models ${ }^{95-97} \cdot \beta$-Adrenergic signalling is involved in heart failure and ageing, and, thus, a better understanding of the mechanisms underlying the differential responses between the sexes to stress stimuli is needed.

Analysis and characterization of calcium handling can be monitored in real time using calcium indicator dyes or reporter lines and optical mapping ${ }^{98}$. Optical mapping can visualize the propagation of calcium waves in tissues, allowing the calculation of calcium transient kinetics (amplitude, duration, decay time and conduction velocity). Optical mapping can also be used to identify functional abnormalities, such as spiral waves, which indicate arrhythmia ${ }^{99}$. Agents, such as caffeine, can be applied to induce $\mathrm{Ca}^{2+}$ pulses to measure particular parameters, including sarcoplasmic reticulum calcium content and release. Finally, as calcium homeostasis is maintained by coordinated function of numerous proteins, such as ion channels and transporters, mechanisms underlying changes in calcium handling can also be evaluated through interrogation of individual proteins, by introducing calcium channel blockers into the culture media or by editing the cell genome to knock out particular proteins.

Energy metabolism. Cardiac mitochondria in murine female cardiac tissue are greater in number, larger, more elongated and less fragmented than those in male tissue $^{100}$. Regulated by oestrogen, mitochondrial biogenesis is disrupted by OVX, resulting in downregulation of the expression of associated genes, such as peroxisome proliferator-activated receptor- $\gamma$ co-activator (PGC1 $\alpha$ ) and nuclear respiratory factor 1 (NRF1) ${ }^{101}$. Loss of oestrogen also causes substantial mitochondrial swelling, which can be counteracted by supplementation of oestrogen ${ }^{102}$. OVX is further accompanied by functional changes in the mitochondria, providing evidence that loss of oestrogen leads to mitochondrial dysfunction. OVX causes a reduction in oxidative capacity, a decrease in ATP synthesis and decline in antioxidants, with a significant increase in stress-induced ROS production in the OVX group compared with the control group ${ }^{101,103,104}$.

Compared with females, males have a lower capacity for calcium retention and greater sensitivity to $\mathrm{Ca}^{2+}$-induced mitochondrial permeability transition pore opening, further supporting the cardioprotective role of oestrogen in the heart ${ }^{105-107}$. Gene expression analyses in mice and rats support these findings, revealing considerable sexual dimorphism in cardiac mitochondria at the transcriptional level for genes related to fatty acid metabolism, oxidative phosphorylation and apoptosis ${ }^{108,109}$. Interestingly, these differences in expression are age-dependent. At a young age, genes associated with fatty acid metabolism are upregulated in females compared with males, whereas differences in oxidative phosphorylation mainly appear in old rats, with gene expression indicating a higher oxidative capacity in females than in age-matched males. Although these differences may vary by age and species, sexual dimorphism in cardiac metabolism is evident, owing to the many differences in mitochondrial properties. Oestrogen, in particular, plays an important role, influencing regulation of mitochondrial structure and biogenesis, apoptosis, ATP production, ROS generation and calcium kinetics.

Energy metabolism can be evaluated by longitudinal studies that assess functional changes over time without interrupting cell culture, by monitoring labelled substrates collected from media samples. Metabolite profiles of cell-free supernatants can indicate metabolic shifts between glycolysis and fatty acid metabolism, which is an important determinant of cell maturity ${ }^{110}$. 
Table 2 | Sex-based differences in cardiac disease conditions

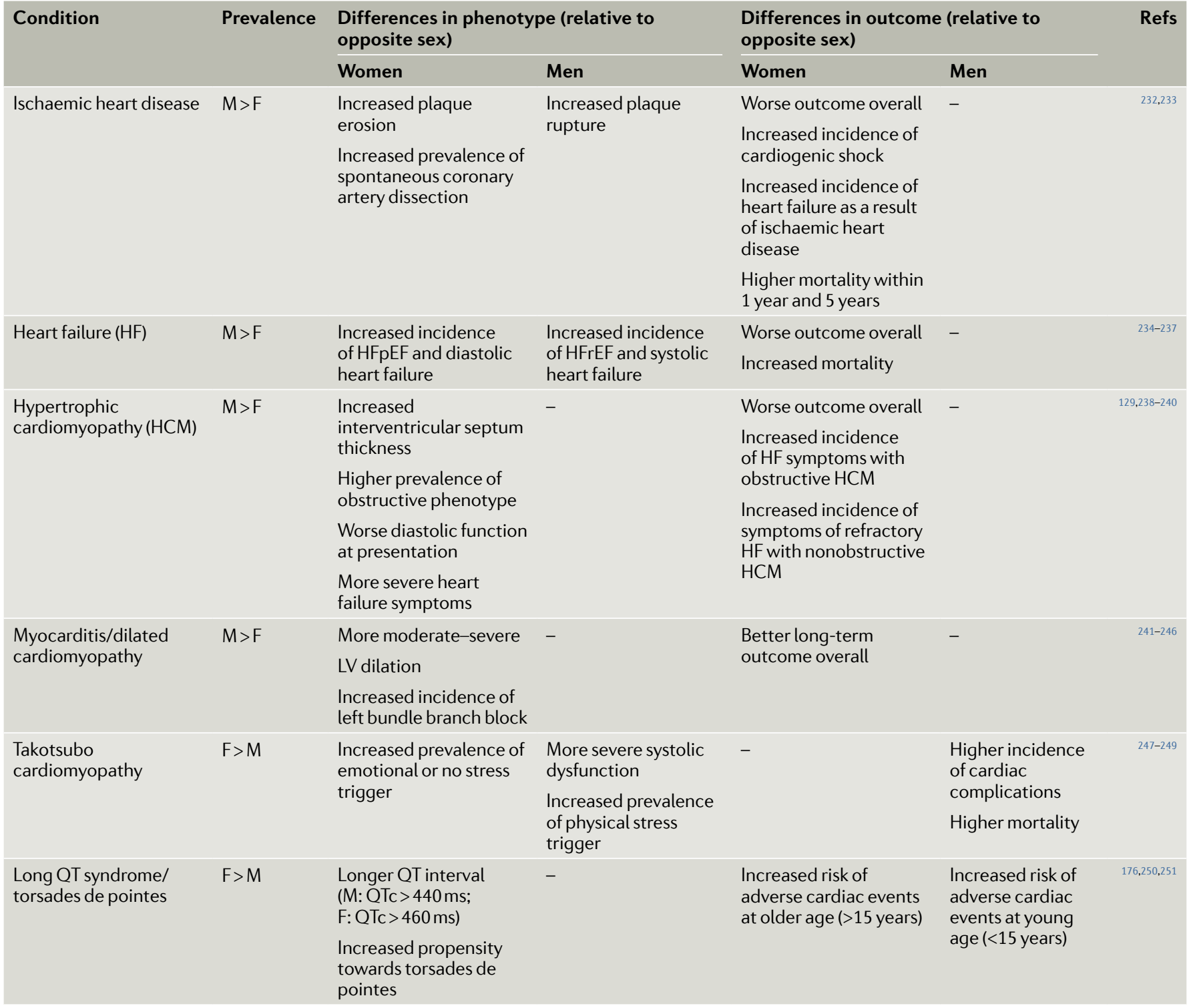

F, female; HFpEF, heart failure with preserved ejection fraction; HFrEF, heart failure with reduced ejection fraction; LV, left ventricle; M, male; QTc, corrected QT interval.

Supernatant can also be tested for changes in cell function by measuring ROS, troponin I and lactate dehydrogenase, indicating oxidative stress levels, cardiomyocyte injury and cell damage, respectively ${ }^{111,112}$. Imaging can reveal mitochondrial density, morphology and subcellular organization in cell populations ${ }^{113}$. Tissues can also be analysed by high-throughput liquid chromatography mass spectrometry, allowing comprehensive profiling of energy metabolism. Biosensors that non-invasively measure glucose and lactate ${ }^{114}$ could also be applied to monitor sex-specific energy metabolism in tissues and assess tissue responses to different factors, such as hormonal changes, in real time and over long culture periods of weeks to months.

Overall, sex-based differences in cardiac physiology are complex, arise from multiple sources and change throughout life, making it challenging to investigate those differences. Although these differences affect nearly every aspect of cardiac function, from contractility to metabolism, they are largely overlooked under homeostatic conditions, because they do not disrupt normal heart function for either sex. However, sex-based disparities at baseline likely contribute to and exacerbate clinically observed differences in disease pathology and drug response.

\section{Cardiac pathologies}

In disease, sex disparities become even more apparent. Owing to the cardioprotective effect of sex hormones and genetic differences, women have considerably less cardiovascular-related diseases than men, which is also reflected in less cardiovascular-disease-related deaths in women $^{115}$. These differences gradually disappear after menopause $\mathrm{e}^{116}$. The sex disparity is relevant in several prevalent conditions (TABLE 2) and for drug efficacy and safety of cardiac therapies, and, thus, should be incorporated in tissue-engineered models of cardiac disease (TABLE 3). 
Table 3 | Tissue-engineered disease models

\begin{tabular}{|c|c|c|c|c|c|c|}
\hline \multicolumn{2}{|c|}{ Cardiac pathological conditions } & $\begin{array}{l}\text { Tissue-engineered disease } \\
\text { model } \\
\text { Cardiac engineered tissue } \\
\text { attached around flexible pillars } \\
\text { in small volume of ischaemic } \\
\text { media to promote metabolic } \\
\text { waste combined with hypoxic } \\
\text { environment (ischaemia), } \\
\text { followed by sudden return to } \\
\text { normal conditions (reperfusion) }\end{array}$ & $\begin{array}{l}\text { Cells } \\
\text { hiPSC-CMs }\end{array}$ & $\begin{array}{l}\text { Biomaterials } \\
\text { Collagen- } \\
\text { fibrinogen } \\
\text { hydrogel }\end{array}$ & $\begin{array}{l}\text { Readouts } \\
\text { Cell death, } \\
\text { contractile force, } \\
\text { conduction velocity, } \\
\text { pH change, ROS } \\
\text { generation }\end{array}$ & $\begin{array}{r}\text { Refs } \\
125\end{array}$ \\
\hline \multirow{4}{*}{ Cardiomyopathy } & & $\begin{array}{l}\text { Cell-matrix mixture seeded } \\
\text { on PDMS mould, leading to } \\
\text { compaction and self-assembly } \\
\text { of cylindrical engineered cardiac } \\
\text { tissues anchored by end posts }\end{array}$ & $\begin{array}{l}\text { hiPSC-CMs derived } \\
\text { from patients with } \\
\text { cardio-facio-cutaneous } \\
\text { syndrome due to an } \\
\text { activating BRAF gene } \\
\text { mutation }\end{array}$ & $\begin{array}{l}\text { Collagen- } \\
\text { Matrigel mix }\end{array}$ & $\begin{array}{l}\text { Tissue size, twitch } \\
\text { force }\end{array}$ & 252 \\
\hline & & $\begin{array}{l}\text { Engineered heart tissue cast } \\
\text { between two hollow elastic } \\
\text { silicone posts, reinforced with } \\
\text { metal braces }\end{array}$ & $\begin{array}{l}\text { Rat ventricular } \\
\text { cardiomyocytes }\end{array}$ & Fibrin & $\begin{array}{l}\text { Contractile dynamics, } \\
\text { collagen I deposition, } \\
\text { cardiomyocyte size }\end{array}$ & 254 \\
\hline & $\begin{array}{l}\text { Mitochondrial } \\
\text { cardiomyopathy } \\
\text { of Barth } \\
\text { syndrome }\end{array}$ & $\begin{array}{l}\text { Cardiac microtissues seeded } \\
\text { on cantilevers to form muscular } \\
\text { thin films }\end{array}$ & $\begin{array}{l}\text { iPSC-CMs derived from } \\
\text { patients with Barth } \\
\text { syndrome }\end{array}$ & Fibronectin & $\begin{array}{l}\text { Mitochondria } \\
\text { respiratory capacity } \\
\text { reserve, sarcomere } \\
\text { morphology, } \\
\text { contractile dynamics }\end{array}$ & 253 \\
\hline & $\begin{array}{l}\text { Dilated and } \\
\text { acquired } \\
\text { cardiomyopathies }\end{array}$ & $\begin{array}{l}\text { Human engineered cardiac } \\
\text { tissues on single-tissue and } \\
\text { multi-tissue bioreactors } \\
\text { to model hereditary } \\
\text { phospholamban-R14 deletion- } \\
\text { dilated cardiomyopathy; and } \\
\text { cryo-injury and doxorubicin- } \\
\text { induced hECT models of } \\
\text { acquired cardiomyopathy }\end{array}$ & hiPSC-CMs & $\begin{array}{l}\text { Collagen- } \\
\text { Matrigel mix }\end{array}$ & Contractile dynamics & 255 \\
\hline \multicolumn{2}{|l|}{ Cardiac fibrosis } & $\begin{array}{l}\text { Biowire II model of interstitial } \\
\text { and focal cardiac fibrosis }\end{array}$ & $\begin{array}{l}\text { hiPSC-CMs co-cultured } \\
\text { with } 75 \% \text { ventricular } \\
\text { cardiac fibroblasts }\end{array}$ & $\begin{array}{l}\text { Fibrin-based } \\
\text { hydrogel }\end{array}$ & $\begin{array}{l}\text { Contractile dynamics, } \\
\text { electrophysiological } \\
\text { function }\end{array}$ & 257 \\
\hline \multicolumn{2}{|c|}{ Torsades de pointes } & $\begin{array}{l}\text { 3D cardiac tissue sheets on a } \\
\text { culture surface grafted with } \\
\text { a temperature-responsive } \\
\text { polymer }\end{array}$ & $\begin{array}{l}\text { hiPSC-CMs and } \\
\text { non-myocytes }\end{array}$ & Collagen & $\begin{array}{l}\text { Contractile dynamics, } \\
\text { extracellular field } \\
\text { potential }\end{array}$ & 258 \\
\hline \multirow{2}{*}{\multicolumn{2}{|c|}{ Drug-induced cardiomyopathy }} & $\begin{array}{l}\text { Biowire platform that combines } \\
\text { 3D cell cultivation around } \\
\text { a suture with electrical } \\
\text { stimulation to investigate the } \\
\text { effect of chronic drug exposure } \\
\text { to isoprenaline, angiotensin II } \\
\text { and endothelin 1 }\end{array}$ & $\begin{array}{l}\text { hESC-CMs and } \\
\text { hiPSC-CMs }\end{array}$ & Collagen matrix & $\begin{array}{l}\text { Cell size, contractile } \\
\text { dynamics, cardiac } \\
\text { troponin secretion }\end{array}$ & 259 \\
\hline & & $\begin{array}{l}\text { Cardiac tissues stretched } \\
\text { between two flexible pillars } \\
\text { providing mechanical forces, } \\
\text { subjected to electrical } \\
\text { stimulation to induce } \\
\text { contractions }\end{array}$ & hiPSC-CMs & Fibrin hydrogel & Beat frequency & 26 \\
\hline
\end{tabular}

BNP, brain natriuretic peptide; $h E C T$, human engineered cardiac tissue; $h E S C$, human embryonic stem cell; hESC-CMs, hESC-derived cardiomyocytes; hiPSC, human induced pluripotent stem cell; hiPSC-CMs, hiPSC-derived cardiomyocytes; PDMS, polydimethylsiloxane; POMaC, poly(octamethylene maleate (anhydride) citrate); ROS, reactive oxygen species. 
Ischaemic cardiac diseases. Sex-based disparities in ischaemic cardiac disease are evident in humans and animals, with females more inclined to have vascular damage during myocardial infarction ${ }^{117}$. Female rats are more tolerant to oxygen deprivation than males ${ }^{118}$, potentially owing to better preserved metabolic capacity and energy production under stress ${ }^{119}$. These protective effects have been attributed to oestrogen. Cardiomyocyte-specific overexpression of oestrogen receptor- $\beta$ improves survival after induced myocardial infarction in both male and female rats ${ }^{120}$. Activation of oestrogen receptor- $\alpha$ in the heart endothelium by an oestrogen-dendrimer conjugate reduces ischaemia-reperfusion injury in mice ${ }^{121}$. In vitro, functional responses of hypertrophic rat cardiac myocytes to ischaemic stress show increased ischaemic resilience, with attenuated reduction of cell shortening and fewer changes in $\mathrm{Ca}^{2+}$ handling in females compared with males ${ }^{96}$. Oestrogen, in the form of $17 \beta$-oestradiol, helped restore mitochondrial activity ${ }^{122}$, and reduce cardiomyocyte apoptosis ${ }^{123}$ and infarct size ${ }^{124}$, consistent with clinical outcomes comparing women and men following myocardial infarction ${ }^{124}$.

Engineered human cardiac tissues can be used to model acute injury; for example, a model of ischaemiareperfusion injury has been established by encapsulating human iPSC-derived cardiomyocytes in a collagen hydrogel (FIG. 3a). These engineered cardiac tissues were exposed to anoxic conditions and allowed to accumulate metabolic waste to mimic nutrient deprivation, hyperkalaemia, high lactate concentration and low extracellular $\mathrm{pH}$ in ischaemia. To model reperfusion, cardiac tissues were switched back to normoxic conditions and media was replenished to re-establish normal $\mathrm{pH}$ and ion balance ${ }^{125}$.

Cardiomyopathy. In cardiomyopathy, women develop more severe concentric hypertrophy with smaller ventricular diameter, greater wall thickness and a better systolic function, whereas men demonstrate more pronounced chamber dilation ${ }^{126}$. Genetic profiling revealed distinct molecular processes involved in men and women during maladaptive left ventricular remodelling. Genes and pathways involved in fibrosis were highly upregulated in overloaded male ventricles, whereas genes and pathways related to the ECM and inflammation were upregulated in overloaded female ventricles ${ }^{127}$. In addition to the effects of oestrogen, intrinsic sex differences in myocardial calcium handling and energy metabolism may also contribute to differential remodelling mechanisms ${ }^{128}$.

Hypertrophic cardiomyopathy is characterized by decreased diastolic function and increased interstitial fibrosis, caused by genetic mutations of sarcomere proteins, such as cardiac myosin-binding protein $\mathrm{C}$ (MYPBC3) and myosin heavy chain 7 (MYH7) ${ }^{129,130}$. Female patients tend to have a higher degree of interstitial fibrosis, a lower passive stiffness of cardiomyocytes owing to higher expression of a more compliant isoform of titin and reduced capillary density ${ }^{129,130} \mathrm{com}$ pared with male patients. In rat models, males with hypertrophic cardiomyopathies are more responsive to $\beta$-adrenoceptor stimulation than females ${ }^{96}$. Two polymorphisms in oestrogen receptors have been associated with increased left ventricular mass and wall thickness in female patients, indicating a role for oestrogen $^{131}$.

Myocarditis, or myocardial inflammation, and resulting dilated cardiomyopathy are $50 \%$ more common in men than in women ${ }^{132}$. COVID-19-related studies suggest a higher rate of acute myocarditis in men than in women, with cardiac injury markers (troponin, myoglobin, brain natriuretic peptide, creatine kinase-myocardial band fraction test) expressed at higher levels in male patients ${ }^{133,134}$. This disparity may result from sex-specific immune responses to virus infection and subsequent injury ${ }^{135}$. Across species, females commonly develop more sensitive innate and adaptive immune responses than males, facilitating faster progression of inflammation towards tissue remodelling and restoration of homeostasis. Accelerated immune responses in females favour the resolving of inflammation caused by cardiac injury, suggesting protective effects of oestrogen ${ }^{136,137}$. In addition, in a clinical study, genes associated with energy transduction and antioxidant activity were upregulated in female patients, suggesting higher metabolic capacity and energy production under stress ${ }^{119}$ than in male patients. These results may inform the design of sex-specific therapeutic strategies.

Takotsubo (stress) cardiomyopathy primarily occurs in postmenopausal women, comprising close to $90 \%$ of all reported cases, with symptoms similar to acute coronary syndrome ${ }^{138,139}$. The root cause of the disease is unclear, and its onset is commonly related to emotional and physical triggers. Clinical evidence suggests that high levels of stress hormones (noradrenaline, adrenaline, dopamine) cause negative inotropy and left ventricular contractile dysfunction through $\beta 2$-adrenoceptors ${ }^{139}$. The cardioprotective effects of oestrogen showed high correlation to the aetiology of the syndrome in rodent models ${ }^{138,140}$.

Torsades de pointes. Longer systole duration and longer QT intervals in women lead to a higher risk of torsades de points ${ }^{141}$ compared with men. By contrast, men are at a higher risk of short QT syndrome ${ }^{142}$. Human iPSCderived cardiomyocytes from male and female donors can be used to recapitulate these sex-related differences in vitro. Female cardiomyocytes show significantly steeper slopes of field potential durations (FPDs) to interspike interval ratios and a higher sensitivity to cardiac delayed rectifier (IKr) blocker-induced FPD prolongation. Sex hormones also affect FPD; $17 \beta$-oestradiol increases FPD and $5 \alpha$-dihydrotestosterone shortens FPD. However, the addition of sex hormones has a limited effect on the responses of human iPSC-derived cardiomyocytes to IKr blockade and cannot explain the higher proarrhythmic tendency in women than in men $^{50}$. A ring-shaped engineered heart tissue model (FIG. 3d) can be used to establish an atrial arrhythmia model, controlled by an electrical field potential. Application of the electrical field potential terminates the arrhythmic activity of the atrial engineered heart tissue, converting the arrhythmia into normal activity with synchronous AP propagation ${ }^{28}$. 
Drug efficacy and toxicity. Owing to the sex-specificity of cardiac pathophysiology, drug efficacy and toxicity have been reported to differ in men and women ${ }^{143,144}$. Women are at a nearly twofold higher risk for adverse drug reaction than men across all drug classes ${ }^{145}$. Drug regimens also differ between the sexes. For example, in the case of hypertrophic cardiomyopathies, men are more commonly prescribed beta blockers ( $80 \%$ for men versus $58 \%$ for women), whereas women are more frequently prescribed calcium channel blockers $(58 \%$ versus $27 \%$ ) and dual therapy (38\% versus $20 \%)^{130}$. Owing to differential metabolic enzyme secretion, cardiovascular drugs can have different pharmacokinetics and pharmacodynamics in men and women. Many cardiovascular drugs are metabolized by enzymes of the cytochrome P450 (CYP) monooxygenase system ${ }^{146}$. Sex differences in the expression of CYP1A2, CYP2D6, CYP2E1 and CYP3A4 are particularly relevant in cardiovascular medication; for example, verapamil has a faster clearance rate in women than in men, owing to higher CYP expression ${ }^{147}$.

Despite the complex, long and expensive process of drug discovery, many non-cardiovascular medicines had to be withdrawn from the market, because they caused risks to patients, mainly cardiotoxicity. Although sex differences are implemented in the experimental design of clinical trials, sex-specific regulations for in vitro or preclinical studies remain elusive. Stratifying by sex leads to more informative results in clinical trials. Notably, the oestrogen-dependent efficacy of the phosphodiesterase type 5 (PDE5) inhibitor sildenafil was only revealed in clinical trials, and not in preclinical studies ${ }^{148}$. The higher cardiotoxicity of sunitinib in women, caused by reduced expression of drug efflux transporters and suppressed receptor tyrosine kinases, was demonstrated in in vitro cultures and animal models ${ }^{149}$. Engineered cardiac tissues could be used in parallel with animal studies to better validate drug safety before clinical studies. Moreover, refining engineered cardiac tissues by including both sexes would remove biased results, expediting drug development. In addition, gene editing and stem cell technologies enable the generation of customized, genetically modified disease cell lines for studying sex-specific diseases (TABLE 3).

\section{Design criteria for sex-specific models}

Cardiac models based on engineered human cardiac tissues would have several advantages for the study of sex-specific differences in cardiac (patho)physiology. First, human-based models are not limited by species-specific effects inherent to animal studies. iPSC technology ${ }^{150}$ allows implementation of patient specificity ${ }^{30,151-153}$, providing an essentially unlimited source of patient-specific cells, which can be expanded and differentiated into almost any cell type, including cardiac lineages ${ }^{45,46}$. Second, understanding the roles of sex-related factors in clinical and preclinical studies is challenging, owing to confounding variables. Sex-specific tissues enable control of such environmental and behavioural factors to study genetic, epigenetic and hormonal variables. Third, experimental variables can be optimized, for example, the timing and dosage of hormone conditioning. The cellular microenvironment can be manipulated by modulating the stiffness, degradation and composition of biomaterials to mimic properties of the heart matrix in health or disease. Gene editing can be used to knock out particular genes to create or correct disease models. These advantages allow quantitative, mechanistic studies of sex-specific differences in cardiac physiology in vitro (FIG. 3).

\section{Cells}

iPSCs can be derived from male and female patients and differentiated into the different types of cell comprising the heart muscle ${ }^{45-48}$. X chromosome dosage and sex affect iPSC differentiation and cardiac fate outcomes ${ }^{51}$, and, therefore, iPSC-based engineered tissues might differ on the molecular, ultrastructural and functional levels, even without the addition of sex hormones. Moreover, as the cellular landscape in cardiac tissues differs between men and women, adequate ratios of cardiomyocytes and supporting cells should be considered to recapitulate in vivo cell composition ${ }^{43}$.

\section{Soluble factors}

Sex-based differences in cellular responses to soluble factors have been observed in several diseases ${ }^{154,155}$. Notably, sex-specific differences have been reported in valvular interstitial cell (VIC) responses to conditioning with serum derived from male versus female patients both pre and post transcatheter aortic valve replacement (TAVR). VICs pretreated with male pre-TAVR serum showed reduced ability to deactivate when in male post-TAVR serum relative to VICs treated with female serum ${ }^{156}$. Therefore, growth factors, cytokines and exosomes in the cell environment should be included in sex-specific studies ${ }^{157}$. The source of sera is often not reported for cell culture experiments and, thus, chemically defined supplements should be used. Importantly, phenol red, a commonly used $\mathrm{pH}$ indicator dye, should be removed from basal media because of its oestrogen-like bioactivity ${ }^{158}$.

In addition to controlling the base media and identifying sex-specific soluble factors, the timing of their administration and dosage should be considered. For healthy adult tissues, physiological hormone levels should be mimicked, matching clinical data. In healthy adult men, serum concentrations of testosterone range between 300 and $1,000 \mathrm{ng} \mathrm{dl}^{-1}$, and remain at a constant level throughout adulthood ${ }^{39,159}$. Hormone conditioning is more complicated in women; ideally, the temporal variations in hormone levels throughout the menstrual cycle should be recapitulated, with $\beta$-oestradiol and progesterone levels fluctuating between 30 and $800 \mathrm{pg} \mathrm{ml}^{-1}$ and 1 and $20 \mathrm{ng} \mathrm{ml}^{-1}$, respectively ${ }^{160,161}$.

Biomaterials can be functionalized with bioactive molecules to increase cell attachment and growth ${ }^{162,163}$. Similarly, instead of supplementing media with hormones or other sex-specific soluble factors, biomaterials could be modified to deliver hormones by physical absorption, covalent binding or microparticle delivery ${ }^{164,165}$. For example, sequential release of oestrogen and progesterone from a biomaterial could mimic temporal variations in hormone levels in women. 
Alternatively, on-demand release of sex-specific soluble factors from biomaterials could be achieved by external stimuli, such as a magnetic field or light ${ }^{166,167}$. Alternatively, flexible electronics could be applied to tissues for triggered release of sex-specific factors at a desired time and location ${ }^{168}$. Microfluidic devices could also be harnessed to administer hormones to engineered tissues in a controlled manner ${ }^{169}$. For example, female organs have been engineered to study women's health (BOX 1), featuring integrated platforms with tissues capable of physiologically relevant hormone secretion ${ }^{170-174}$. Notably, a microfluidic culture model can reproduce the hormone profile of the human 28 -day menstrual cycle ${ }^{171}$. Integrated with engineered cardiac tissues by perfusion, this platform could provide sustained hormone signalling and induce sex-specific effects without the need for external supplementation. Of note, many microfluidic devices are made of polydimethylsiloxane (PDMS) ${ }^{175}$, which is biocompatible, transparent and easy to use; however, PDMS absorbs hydrophobic molecules and may, thus, change available concentrations of soluble factors. Therefore, more inert elastomers should be used for studies involving sex hormones.

\section{Box 1 | Bioengineered models to study women's health and disease}

Bioengineered organs-on-chips have been developed to address the many unmet needs in the area of women's health. For example, a 3D tissue model has been designed, termed EVATAR, which imitates the human female 28-day menstrual cycle hormone profile and allows organ-organ communication through hormonal signals. The system includes engineered decellularized endometrial scaffolds to provide the structure of the native tissue-like environment and promote cellular interactions leading to tissue formation. In addition, female mouse ovaries and human reproductive tissues are used to design ovarian, fallopian, uterine, cervical and hepatic microtissue modules. These modules are then connected by microfluidic channels to provide the required nutrients and to remove the metabolic waste. Addition of follicle-stimulating hormone causes the ovary module to produce oestrogen. On day 14 , luteinizing hormone is provided to cause the ovary module to start producing progesterone and stop producing oestrogen. This dynamic microfluidic device provides female steroid and peptide hormones to other tissue modules, which respond as they normally would in the female body ${ }^{171}$.

Decellularized endometrial scaffolds can also be used in a 3D endometrial model recapitulating the crucial hallmarks of the menstrual cycle changes of a human endometrium. This model provides a more physiologically relevant setting to study the physiology and pathophysiology of the innermost lining layer of the woman's uterus compared with cell monolayers. The 3D endometrium is fabricated from decellularized endometrial extracellular matrix (ECM), which is then recellularized by endometrial cells and treated with oestrogen and progesterone to induce the secretion of the decidual markers insulin-like growth factor-binding protein 1 (IGFBP1) and prolactin, in response to addition of dibutyryl cyclic adenosine monophosphate (cAMP) ${ }^{277}$.

A mucosal barrier tissue model allows investigation of the mucosal barrier function and of diseases, such as HIV and infertility. The model is based on a hybrid ECM hydrogel consisting of poly(ethylene glycol) macromers, adhesion peptides that connect the epithelial and stromal cells, peptides that bind the ECM of each cell type and crosslinkers. Endometrial epithelial and stromal cells can be co-cultured in the mucosal barrier model and the ECM hydrogel is easy to fabricate and can be applied in other applications in mucosal barrier tissue engineering ${ }^{278}$.

A multilayer engineered ovarian tissue secreting sex steroids and peptide hormones in response to gonadotropins was designed as hormone replacement therapy. The native follicular structure can be recapitulated by encapsulating theca and granulosa cells, isolated from rat ovaries, in multilayer alginate microcapsules, with granulosa cells in the inner layer and theca cells in the outer layer, separated by a layer of poly-L-ornithine. The 3D arrangement allows nutrient and waste exchange, crosstalk between cell types and sustained release of key sex hormones for 30 days $^{173}$.

\section{External stimuli}

Electrical stimulation is well established in cardiac tissue engineering. Extended regimens of electrical pacing are used to mature cardiac tissues towards a more adult-like phenotype ${ }^{26,27}$. Electrical stimulation can also help elucidate sex-specific cardiac phenotypes. In rats, sex differences in contractility are more pronounced at rapid pacing rates $^{78}$. However, a study in rabbits showed that in the context of long QT syndrome, pacing at rapid rates eliminates the sex differences seen in the electrocardiogram ${ }^{176}$. For example, exercise-induced cardiac hypertrophy is more predominant in female rodents than in males, although this hypertrophic response is different from that observed in pathological hypertrophy ${ }^{177}$. Whether electrical pacing differentially affects male and female tissues remains to be explored; of note, the frequency of electrical stimulation of cardiac tissue may be important, because it could either reveal or obscure sex-based differences.

\section{Biomaterials}

In the heart, cells are surrounded by the cardiac ECM, which is a hierarchically organized network of fibres. The ECM plays a crucial role in controlling cell migration, proliferation, differentiation and assembly into cardiac tissues ${ }^{13,59,178,179}$. A myriad of physical and biochemical signals are transmitted by the cardiac ECM and sensed by receptors on cardiac cells, in which they activate signalling pathways to regulate cellular behaviours ${ }^{179,180}$. The molecular, structural and mechanical properties of the cardiac ECM play important roles in promoting cell assembly into an aligned syncytium, enabling anisotropic electrical signal propagation and orchestrating cardiac tissue contractions ${ }^{181}$. The cardiac ECM can be harnessed or mimicked to generate functional cardiac tissues ${ }^{59,62,182-184}$; for example, cardiac cells are able to repopulate a decellularized whole heart and restore some pump function, indicating the capability of the native ECM to guide tissue assembly ${ }^{185}$. Biochemical cues on the native ECM further provide cells with a protective microenvironment, support their growth and function, and promote heart regeneration following myocardial infarction ${ }^{178,186,187}$. Moreover, recapitulating the mechanically anisotropic, honeycomb-like structure of the endomysial fibres or the spring-like perimysial fibres improves cardiac tissue functionality ${ }^{188,189}$.

Material-based scaffolds can be customized to design biomaterials recapitulating the male and female cardiac microenvironment ${ }^{190-192}$. For cardiac tissue engineering, biomaterials need to be mechanically stable while allowing tissue contractions, promoting cell spreading and elongation, and supporting the formation of a tissue with electrical signal propagation. Synthetic materials, natural materials and decellularized hearts have been explored for cardiac tissue engineering, each with advantages and disadvantages, depending on the biological question and goal of the sex-specific study.

Synthetic polymers, such as poly(DL-lactic-co-glycolic acid), poly(glycerol sebacate), polycaprolactone and poly(ethylene glycol), can be fabricated into hydrogels or electrospun into fibrous scaffolds for cardiac tissue engineering ${ }^{193}$. Synthetic materials are readily available 
and they can be easily manipulated to tune their mechanical properties. In addition, many synthetic polymers are biodegradable and biocompatible, and their fabrication is highly reproducible. However, they lack biochemical cues for cell attachment and functional maturation. Importantly, the low remodelling rates of synthetic materials would limit tissue remodelling studies of male and female tissues, an aspect of particular interest.

Natural polymers, such as collagen, gelatin, fibrin and Matrigel, are used to fabricate hydrogels, macroporous and fibrous scaffolds, and as biological inks to print tissues. Natural polymers are also readily available, support cell adhesion and spreading, and have high remodelling rates. Furthermore, the properties of natural materials could be tailored to mimic sex-specific features, such as stiffness as well as protein and glycoaminoglycan content. For example, collagens of the cardiac ECM vary by age and sex, with more collagen type I, III and IV expressed in male cardiac tissues than in female tissues at a young age $^{55}$. Male and female tissues could be fabricated using different combinations of collagens to match the native ECM properties. Of note, the source and properties, especially the sex of the original biological source of commercially available collagens should be reported, because they play an important role in sex-specific research.

It is impossible to fully recapitulate the complexity of the cardiac ECM. Therefore, decellularized heart ECM is often used as scaffold to preserve the native biochemical and structural properties of the heart. The importance of organ-specific ECM has been demonstrated for heart, lung and liver tissue engineering ${ }^{194-196}$, with differences in male and female ECM architecture, mechanical properties and composition, including different remodelling and regenerative capabilities upon injury or disease $\mathrm{s}^{55,56,127,197,198}$. Decellularized heart ECM has great potential to study sex-specific microenvironments and their effects on cells; for example, to investigate whether sex-specific ECM has differential effects on male and female cells. Cardiac ECM for tissue engineering is mostly sourced from rodents and swine, where sex is often not disclosed, and species-specific differences may still be present ${ }^{199,200}$. Harvesting human cardiac tissues, for example, by endomyocardial biopsy or using tissue from hearts not suitable for transplantation that are otherwise healthy, would allow the generation of male and female ECM that preserves the distinct human ECM architecture and mechanics. Alternatively, ECM could be digested to form hydrogels, in which only the biochemical composition is preserved.

The specificity of the ECM is especially important for disease modelling, because many diseases show sex-based differences in cardiac remodelling and fibrosis ${ }^{130,201,202}$. For example, in hypertrophic cardiomyopathy, women show more ECM remodelling than $\operatorname{men}^{130}$. Sex-specific tissue models would, thus, markedly increase the mimicry of specific disease phenotypes, enabling the study and control of sex-related differences.

\section{Study design}

Designing sex-specific studies for cardiac disease investigations is challenging. Sample size is important and a large number of cell lines may be required, similar to clinical trials. In vitro studies of sex-based differences have to consider the variability between cell lines, necessitating a power analysis to ensure statistical significance. For example, high variability between baseline phenotypes of iPSC-derived cardiomyocytes has been reported $^{203}$. The timescale also has to be considered, because time is a limiting factor in vitro. In vivo, sex differences may slowly accumulate over decades of hormone conditioning, whereas in vitro studies are typically conducted on the scale of weeks or sometimes months. Therefore, it needs to be explored how long engineered tissues must be cultured to achieve sex-specific phenotypes.

Sex-specificity can be implemented into studies of cardiac (patho)physiology with engineered cardiac tissues by modulation of cells, ECM, soluble factors and external stimuli. However, the numbers and combinations of sex-specific components required to adequately capture sex-dependent physiology and clinical outcomes remain to be explored. These studies will rely on knowledge acquired in functional and mechanistic studies, as well as on rigorous benchmarking to data gathered in clinical studies. Although in vitro tissue models are unable to capture complex organismal behaviours, they afford a high level of control, with the potential to provide new insights into sexual dimorphisms observed in the clinic.

\section{Applications and outlook}

Incorporating sex-specificity into engineered cardiac tissue models and investigating the influence of sex on disparities in cardiac (patho)physiology would serve many purposes. A thorough mechanistic understanding of cardiac diseases would allow the development of targeted treatments for both sexes. In addition, sex-specific platforms could be used for drug screening to identify sex differences in cardiac responses to drugs prior to clinical trials. Sex-specific engineered cardiac tissues could also potentially enable studies of the effects of exogenous supplementation of sex hormones on tissues fabricated from cells derived from the opposite sex. Disparities in cardiac-associated risks occurring in transgender populations may then be explained to make gender-affirming hormone therapy safer. Furthermore, effects of pregnancy (that is, changes in hormone status) and ageing on the heart could be investigated. In particular, the temporal control of in vitro platforms enables the study of the effects of timing and duration of hormone replacement therapy on cardiac function ${ }^{204}$.

\section{Translational impact of sex-specific research}

Sex-specific research could also have an impact on translational research. In addition to tissue models, cardiac tissue engineering aims at regenerating or replacing injured or diseased heart tissue ${ }^{205-207}$. Interestingly, sex-specificity may play an important role in tissue engraftment and replacement. Reduced survival after heart transplantation has been associated with donorrecipient sex mismatch, especially for male recipients of female donor organs, with sex mismatch increasing mortality independently of recipient-donor heart weight match $^{208-212}$. The impact of sex mismatching may also 
apply to engineered tissue patches or grafts fabricated for implantation. Whether matching the sex of the tissue-engineered product to the recipient is required or whether further conditioning for sex-specificity would be beneficial remains to be explored.

\section{Increasing model complexity for sex-specific applications}

Cardiac tissue engineering has greatly advanced, from engineering myocardial tissue to engineering organ-level structures. Integration of sex-specificity into more complex models of the heart would increase the ability to recapitulate clinical phenotypes seen at the organ level. For example, magnetic resonance imaging and micro-computed tomography imaging of male and female patients could inform tissue models and facilitate reproduction of sex-specific differences in the cardiac anatomical structure.

Vasculature. Cardiac tissue models with biologically relevant and functionally matured vasculature remain elusive thus far. Vascular tone, regulated by the reninangiotensin-aldosterone system (RAAS) and nitric oxide synthases, can be considerably influenced by sex hormones ${ }^{213}$ and abundances of X-chromosomelocated proteins ${ }^{214-216}$. Differences in vascular tone may affect local oxygen and nutrient delivery, vascular barrier function and stromal cell behaviours, resulting in sex-specific mechanisms of cardiovascular diseases. For example, coronary heart diseases in women are linked to microvascular spasms and vasoconstriction, whereas in men, they are linked to coronary occlusion and deposition of plaque ${ }^{217}$. Haemodynamic overload, such as hypertension, induces cardiac remodelling and triggers sex-specific adaptation, with women developing hypertrophic remodelling with systolic function and ejection fraction better preserved compared with men ${ }^{218}$. Therefore, incorporation of vascular networks into cardiac tissue models will increase the mimicry of the sexspecific tissue microenvironment. Vasculogenic factors of interest include hydrostatic pressure, vascular smooth muscle tone, solute transport and biological interactions between endothelial, stromal and immune cells. Control over these parameters would enable investigation of sex-specific mechanisms in cardiovascular diseases, hypertension, atherosclerosis, stroke and aneurysms ${ }^{213}$.

Multi-organ systems. Beyond the heart, sex-specific differences have been reported for other organs. For example, tissue-specific, sex-biased gene expression and regulation have been reported across 44 different human tissues, with at least $37 \%$ of genes differentially expressed between sexes in at least one of the tissues ${ }^{219}$. Organ-on-a-chip technologies can model the functionality of organs, including liver, lung, kidney, vasculature, gut and brain, and iPSCs can be incorporated in these platforms to engineer patient-specific tissues to study disease mechanisms and for precision medicine ${ }^{220-225}$. However, sex differences are generally overlooked in these models. The workflow for sex-specific cardiac tissue engineering could also be applied to in vitro models of other organs. Such sex-specific tissue models would provide excellent tools to study sexual dimorphisms in organ pathophysiology, which is crucial for precision medicine and drug development.

Importantly, sex-specific organ models could be integrated into larger systems. Although mechanistic insights into sex-based dimorphism in individual organs will provide the basis for precision medicine and drug development, organs in the human body do not function independently, and an affected organ system can influence multiple other tissues. For example, the RAAS is a hormone system essential for the regulation of blood pressure and fluid balance in the body. RAAS dysfunction is closely related to hypertension, chronic cardiovascular and kidney diseases ${ }^{226}$. The RAAS involves multiple proteins that cycle through organs connected by a common vascular network, including the liver, white adipose tissue (angiotensinogen), kidney (renin), lung (angiotensin-converting enzyme (ACE)) and adrenal gland (aldosterone).

Sex dimorphisms manifest themselves in different plasma levels of these proteins and different receptor densities in multiple organs and in the vascular endothelium. Angiotensin II, converted from angiotensinogen by renin and ACE, can induce pathological hypertrophy of cardiomyocytes, acting as a vessel constrictor and inducing the secretion of aldosterone, causing water retention in the kidney distal tubules ${ }^{216}$. Oestrogen reduces plasma levels of angiotensin II by increasing the production of the $\mathrm{N}$-terminal angiotensin II fragment (Ang-(1-7)), which leads to a decrease in the activity of $\mathrm{ACE}^{214}$ and a change in extracellular volume, vascular filtration and blood pressure ${ }^{217}$. Consequently, risks of hypertension are lower in premenopausal women than in men, but are similar between postmenopausal women and men $^{227}$. Therefore, modelling RAAS in vitro would require high-fidelity, multi-hierarchical vascular networks that link liver, kidney, lung, adrenal gland, heart and reproductive organs in a biologically relevant manner, in terms of sizes and order. Moreover, in sex-specific tissue models of RAAS, adequate tissue function needs to be established, such as renin secretion and salt regulation of kidney tissues, protein production and drug metabolism in liver tissues, ACE production and $\mathrm{O}_{2} / \mathrm{CO}_{2}$ exchanges in lung tissues, contractile function of the heart, as well as hormone production from female or male reproductive systems. These tissue-specific functions need to be benchmarked using sex-specific clinical results and drug responses. For example, blockage of the angiotensin II receptor may be considered a good choice in female patients, because ACE inhibitors used for blood pressure management in male patients are less likely to have similar therapeutic benefits in female patients, owing to lower ACE activity ${ }^{228}$. Thus, in vitro multi-organ models would be beneficial for developing sex-specific, personalized therapeutic strategies for RAAS diseases. Similarly, different organs could be combined for customized multi-organ systems for various biological questions. Multi-organ-systems-on-a-chip would be particularly important for modelling drug absorption, distribution, metabolism and excretion, and for studying diseases and drugs with systemic effects, such as chemotherapy. 
In summary, sex can influence nearly every aspect of the heart, from gene expression to cellular composition and function. By focusing on differences at the cell and tissue levels, we proposed a framework for recapitulating sex-specific traits in cardiac tissues. Sex as a biological variable has been largely overlooked in tissue engineering thus far, despite numerous differences observed in the clinic. Incorporating sex-specificity will allow the development of male and female cardiac tissue models, towards the goal of personalized medicine, based on innovations in human stem cell technology and tissue engineering, without ethical constraints.

Published online 20 October 2021
1. Benjamin, E. J. et al. Heart disease and stroke statistics-2019 update: a report from the American Heart Association. Circulation 139, e56-e528 (2019).

2. Gao, Z., Chen, Z., Sun, A. \& Deng, X. Gender differences in cardiovascular disease. Med. Nov. Technol. Devices 4, 100025 (2019).

3. Geller, S. E., Koch, A., Pellettieri, B. \& Carnes, M. Inclusion, analysis, and reporting of sex and race/ ethnicity in clinical trials: have we made progress? J. Womens Health 20, 315-320 (2011).

4. Liu, K. A. \& Mager, N. A. D. Women's involvement in clinical trials: historical perspective and future implications. Pharm Pract. 14, 708 (2016)

5. Mazure, C. M. \& Jones, D. P. Twenty years and still counting: including women as participants and studying sex and gender in biomedical research. BMC Womens Health 15, 94 (2015).

6. National Institutes of Health (NIH). NIH Policy and Guidelines on The Inclusion of Women and Minorities as Subjects in Clinical Research. $\mathrm{NIH}$ https://grants. nih.gov/policy/inclusion/women-and-minorities/ guidelines.htm (2017).

7. National Institutes of Health (NIH). Consideration of Sex as a Biological Variable in NIH-funded Research. Notice Number NOT-OD-15-102. NIH https://grants. nih.gov/grants/guide/notice-files/not-od-15-102.htm (2015).

8. National Institutes of Health (NIH). Sex \& Gender. Office of Research on Women's Health. NIH https://orwh.od.nih.gov/sex-gender.

9. Pessôa, B. S. et al. Angiotensin II type 2 receptor-and acetylcholine-mediated relaxation. Hypertension 66 396-402 (2015).

10. Ji, H. et al. Sex chromosome effects unmasked in angiotensin II-induced hypertension. Hypertension 55 1275-1282 (2010)

11. Alzahrani, T. et al. Cardiovascular disease risk factors and myocardial infarction in the transgender population. Circ. Cardiovasc. Qual. Outcomes 12, e005597 (2019)

12. Connelly, P. J. et al. Gender-affirming hormone therapy, vascular health and cardiovascular disease in transgender adults. Hypertension 74, 1266-1274 (2019).

13. Fong, A. H. et al. Three-dimensional adult cardiac extracellular matrix promotes maturation of human induced pluripotent stem cell-derived cardiomyocytes. Tissue Eng. Part A 22, 1016-1025 (2016).

14. Zhang, D. et al. Tissue-engineered cardiac patch for advanced functional maturation of human ESC-derived cardiomyocytes. Biomaterials 34, 5813-5820 (2013).

15. Tiburcy, M. et al. Defined engineered human myocardium with advanced maturation for applications in heart failure modeling and repair. Circulation 135, 1832-1847 (2017).

16. Shadrin, I. Y. et al. Cardiopatch platform enables maturation and scale-up of human pluripotent stem cell-derived engineered heart tissues. Nat. Commun. 8, 1825 (2017).

17. Caspi, O. et al. Tissue engineering of vascularized cardiac muscle from human embryonic stem cells. Circ. Res. 100, 263-272 (2007).

18. Mihic, A. et al. The effect of cyclic stretch on maturation and 3D tissue formation of human embryonic stem cell-derived cardiomyocytes. Biomaterials 35, 2798-2808 (2014).

19. Ruan, J. L. et al. Mechanical stress conditioning and electrical stimulation promote contractility and force maturation of induced pluripotent stem cell-derived human cardiac tissue. Circulation 134, 1557-1567 (2016).

20. Leonard, A. et al. Afterload promotes maturation of human induced pluripotent stem cell derived cardiomyocytes in engineered heart tissues. J. Mol. Cell. Cardiol. 118, 147-158 (2018)

21. Sidorov, V. Y. et al. I-Wire Heart-on-a-Chip I: Threedimensional cardiac tissue constructs for physiology and pharmacology. Acta Biomater. 48, 68-78 (2017).
22. Nunes, S. S. et al. Biowire: a platform for maturation of human pluripotent stem cell-derived cardiomyocytes. Nat. Methods 10, 781-787 (2013).

23. Hirt, M. N. et al. Functional improvement and maturation of rat and human engineered heart tissue by chronic electrical stimulation. J. Mol. Cell. Cardiol. 74, 151-161 (2014).

24. Chan, Y. C. et al. Electrical stimulation promotes maturation of cardiomyocytes derived from human embryonic stem cells. J. Cardiovasc. Transl Res. 6, 989-999 (2013)

25. Godier-Furnémont, A. F. G. et al. Physiologic forcefrequency in engineered heart muscle by electromechanical stimulation. Biomaterials 60 82-91 (2015).

26. Ronaldson-Bouchard, K. et al. Advanced maturation of human cardiac tissue grown from pluripotent stem cells. Nature 556, 239-243 (2018).

Engineered cardiac tissues that undergo intensitypaced electrical stimulation promote extensive maturation of both structure and function of cardiac tissue towards an adult-like phenotype.

27. Zhao, Y. et al. A platform for generation of chamberspecific cardiac tissues and disease modeling. Cell 176, 913-927.e18 (2019).

28. Goldfracht, I. et al. Generating ring-shaped engineered heart tissues from ventricular and atrial human pluripotent stem cell-derived cardiomyocytes. Nat. Commun. 11, 75 (2020).

This chamber-specific, ring-shaped engineered cardiac tissue displays distinct chamber-specific phenotypes and can be used to establish an arrhythmia model for cardiac disease modelling.

29. Lemme, M. et al. Atrial-like engineered heart tissue: an in vitro model of the human atrium. Stem Cell Rep. 11, 1378-1390 (2018)

30. Noor, N. et al. 3D printing of personalized thick and perfusable cardiac patches and hearts. Adv. Sci. 6 , 1900344 (2019).

31. MacQueen, L. A. et al. A tissue-engineered scale model of the heart ventricle. Nat. Biomed. Eng. 2 930-941 (2018)

32. Lee, A. et al. 3D bioprinting of collagen to rebuild components of the human heart. Science 365 , 482-487 (2019)

33. Skylar-Scott, M. A. et al. Biomanufacturing of organspecific tissues with high cellular density and embedded vascular channels. Sci. Adv. 5, eaaw2459 (2019).

34. Tsamandouras, N. et al. Integrated gut and liver microphysiological systems for quantitative in vitro pharmacokinetic studies. AAPS J. 19, 1499-1512 (2017).

35. Skardal, A. et al. Multi-tissue interactions in an integrated three-tissue organ-on-a-chip platform. Sci. Rep. 7, 8837 (2017).

36. Maschmeyer, I. et al. A four-organ-chip for interconnected long-term co-culture of human intestine, liver, skin and kidney equivalents. Lab Chip 15, 2688-2699 (2015)

37. Snell, D. M. \& Turner, J. M. A. Sex chromosome effects on male-female differences in mammals. Curr. Biol. 28, R1313-R1324 (2018).

38. Gurvich, C., Hoy, K., Thomas, N. \& Kulkarni, J. Sex differences and the influence of sex hormones on cognition through adulthood and the aging process. Brain Sci. 8, 163 (2018).

39. Decaroli, M. C. \& Rochira, V. Aging and sex hormones in males. Virulence 8, 545-570 (2016).

40. Hartman, R. J. G. et al. Intrinsic transcriptomic sex differences in human endothelial cells at birth and in adults are associated with coronary artery disease targets. Sci. Rep. 10, 12367 (2020).

41. Witt, E. et al. Sex-specific differences in the intracellular proteome of human endothelial cells from dizygotic twins. J. Proteomics 201, 48-56 (2019).

42. Chang, R. K. R., Chen, A. Y. \& Klitzner, T. S. Female sex as a risk factor for in-hospital mortality among children undergoing cardiac surgery. Circulation 106, 1514-1522 (2002).
43. Litviňuková, $M$. et al. Cells of the adult human heart. Nature 588, 466-472 (2020)

44. Squiers, G. T. et al. Cardiac cellularity is dependent upon biological sex and is regulated by gonadal hormones. Cardiovasc. Res. 117, 2252-2262 (2021). Basal sex-specific differences in cardiac cellularity and their regulation by gonadal hormones in male and female mouse hearts are revealed by flow cytometry and immunofluorescence imaging.

45. Lee, J. H., Protze, S. I., Laksman, Z., Backx, P. H. $\&$ Keller, G. M. Human pluripotent stem cell-derived atrial and ventricular cardiomyocytes develop from distinct mesoderm populations. Cell Stem Cell 21, 179-194.e4 (2017).

46. Zhang, $\mathrm{H}$. et al. Generation of quiescent cardiac fibroblasts from human induced pluripotent stem cells for in vitro modeling of cardiac fibrosis. Circ. Res. 125 552-566 (2019).

47. Patsch, C. et al. Generation of vascular endothelial and smooth muscle cells from human pluripotent stem cells. Nat. Cell Biol. 17, 994-1003 (2015).

48. Protze, S. I. et al. Sinoatrial node cardiomyocytes derived from human pluripotent cells function as a biological pacemaker. Nat. Biotechnol. 35, 56-68 (2017).

49. Papp, R. et al. Genomic upregulation of cardiac Cav1.2 $\alpha$ and NCX1 by estrogen in women. Biol. Sex Differ. 8, 26 (2017).

50. Huo, J., Wei, F, Cai, C. Lyn-Cook, B \& Pang L Sexrelated differences in drug-induced QT prolongation and torsades de pointes: a new model system with human iPSC-CMs. Toxicol. Sci. 167, 360-374 (2019).

51. D'Antonio-Chronowska, A. et al. Association of human iPSC gene signatures and $X$ chromosome dosage with two distinct cardiac differentiation trajectories. Stem Cell Rep. 13, 924-938 (2019).

52. Zeng, H., Wang, J., Clouse, H., Lagrutta, A. \& Sannajust, F. HiPSC-CMs from different sex and ethnic origin donors exhibit qualitatively different responses to several classes of pharmacological challenges. J. Pharmacol. Toxicol. Methods 99, 106598 (2019).

53. Robertson, C., Tran, D. D. \& George, S. C. Concise review: maturation phases of human pluripotent stem cell-derived cardiomyocytes. Stem Cells 31, 829-837 (2013).

54. van den Berg, C. W. et al. Transcriptome of human foetal heart compared with cardiomyocytes from pluripotent stem cells. Development 142. 3231-3238 (2015).

55. Dworatzek, E., Baczko, I. \& Kararigas, G. Effects of aging on cardiac extracellular matrix in men and women. Proteomics Clin. Appl. 10, 84-91 (2016).

56. Grilo, G. A. et al. Age- and sex-dependent differences in extracellular matrix metabolism associate with cardiac functional and structural changes. J. Mol. Cell. Cardiol. 139, 62-74 (2020).

57. Theus, A. S. et al. Biomaterial approaches for cardiovascular tissue engineering. Emergent Mater. 2 193-207 (2019)

58. Feinberg, A. W. et al. Controlling the contractile strength of engineered cardiac muscle by hierarchal tissue architecture. Biomaterials 33, 5732-5741 (2012).

59. Kim, D.-H. et al. Nanoscale cues regulate the structure and function of macroscopic cardiac tissue constructs. Proc. Natl Acad. Sci. USA 107, 565-570 (2010).

60. Heras-Bautista, C. O. et al. Cardiomyocytes facing fibrotic conditions re-express extracellular matrix transcripts. Acta Biomater. 89, 180-192 (2019).

61. Zhang, B. et al. Biodegradable scaffold with built-in vasculature for organ-on-a-chip engineering and direct surgical anastomosis. Nat. Mater. 15, 669-678 (2016).

62. Fleischer, S., Shapira, A., Feiner, R. \& Dvir, T. Modular assembly of thick multifunctional cardiac patches. Proc. Natl Acad. Sci. USA 114, 1898-1903 (2017).

63. Kuraitis, D. et al. Functionalization of soft materials for cardiac repair and regeneration. Crit. Rev. Biotechnol. 39, 451-468 (2019). 
64. Dvir, T. et al. Nanowired three-dimensional cardiac patches. Nat. Nanotechnol. 6, 720-725 (2011).

65. Jiang, L. et al. Preparation of an electrically conductive graphene oxide/chitosan scaffold for cardiac tissue engineering. Appl. Biochem. Biotechnol. 188 952-964 (2019)

66. Ahadian, S. et al. Moldable elastomeric polyestercarbon nanotube scaffolds for cardiac tissue engineering. Acta Biomater. 52, 81-91 (2017).

67. Li, B. et al. A comprehensive mouse transcriptomic BodyMap across 17 tissues by RNA-seq. Sci. Rep. 7 4200 (2017)

68. Trexler, C. L., Odell, A. T., Jeong, M. Y., Dowell, R. D \& Leinwand, L. A. Transcriptome and functional profile of cardiac myocytes is influenced by biological sex Circ. Cardiovasc. Genet. 10, e001770 (2017).

69. Gershoni, M. \& Pietrokovski, S. The landscape of sex-differential transcriptome and its consequent selection in human adults. BMC Biol. 15, 7 (2017).

70. Lopes-Ramos, C. M. et al. Sex differences in gene expression and regulatory networks across 29 human tissues. Cell Rep. 31, 107795 (2020).

71. Mayne, B. T. et al. Large scale gene expression meta-analysis reveals tissue-specific, sex-biased gene expression in humans. Front. Genet. 7, 183 (2016).

72. McLellan Micheal, A. et al. High-resolution transcriptomic profiling of the heart during chronic stress reveals cellular drivers of cardiac fibrosis and hypertrophy. Circulation 142, 1448-1463 (2020).

73. Wang, T. Y. et al. Human cardiac myosin light chain 4 (MYL4) mosaic expression patterns vary by sex. Sci. Rep. 9, 12681 (2019).

74. Stark, R., Grzelak, M. \& Hadfield, J. RNA sequencing: the teenage years. Nat. Rev. Genet. 20, 631-656 (2019).

75. Byrne, S. M., Mali, P. \& Church, G. M. Genome editing in human stem cells. Methods Enzymol. $\mathbf{5 4 6}$ 119-138 (2014).

76. Hartogh, S. C. D. \& Passier, R. Concise review: fluorescent reporters in human pluripotent stem cells: contributions to cardiac differentiation and their applications in cardiac disease and toxicity. Stem Cells 34, 13-26 (2016)

77. Chung, A. K. et al. Women have higher left ventricular ejection fractions than men independent of differences in left ventricular volume. Circulation 113, 1597-1604 (2006)

78. Parks, R. J. \& Howlett, S. E. Sex differences in mechanisms of cardiac excitation-contraction coupling. Pflugers Arch. 465, 747-763 (2013)

79. Howlett, S. E. Age-associated changes in excitationcontraction coupling are more prominent in ventricular myocytes from male rats than in myocytes from female rats. Am. J. Physiol. Heart Circ. Physiol. 298 H659-H670 (2010).

80. Kijlstra, J. D. et al. Integrated analysis of contractile kinetics, force generation, and electrical activity in single human stem cell-derived cardiomyocytes. Stem Cell Rep. 5, 1226-1238 (2015).

81. Laurila, E., Ahola, A., Hyttinen, J. \& Aalto-Setälä, K Methods for in vitro functional analysis of iPSC derived cardiomyocytes - Special focus on analyzing the mechanical beating behavior. Biochim. Biophys. Acta Mol. Cell Res. 1863, 1864-1872 (2016).

82. Zhu, Y., Ai, X., Oster, R. A., Bers, D. M. \& Pogwizd, S. M Sex differences in repolarization and slow delayed rectifier potassium current and their regulation by sympathetic stimulation in rabbits. Pflugers Arch. 465, 805-818 (2013).

83. Makkar, R. R., Fromm, B. S., Steinman, R. T., Meissner, M. D. \& Lehmann, M. H. Female gender as a risk factor for torsades de pointes associated with cardiovascular drugs. JAMA 270, 2590-2597 (1993)

84. Rautaharju, P. M. et al. Sex differences in the evolution of the electrocardiographic QT interval with age. Can. J. Cardiol. 8, 690-695 (1992).

85. Zhang, Y. et al. Sex-steroid hormones and electrocardiographic QT-interval duration: findings from the third National Health and Nutrition Examination Survey and the Multi-Ethnic Study of Atherosclerosis. Am. J. Epidemiol. 174, 403-411 (2011)

86. Rabkin S. W. Impact of age and sex on QT prolongation in patients receiving psychotropics. Can. J. Psychiatry 60, 206-214 (2015).

87. Drici, M.-D., Knollmann, B. C., Wang, W.-X. \& Woosley, R. L. Cardiac actions of erythromycin: influence of female sex. JAMA 280, 1774-1776 (1998).

88. Bai, C.-X., Kurokawa, J., Tamagawa, M., Nakaya, H. \& Furukawa, T. Nontranscriptional regulation of cardiac repolarization currents by testosterone. Circulation $112,1701-1710$ (2005).
89. Liu, X.-K. et al. In vivo androgen treatment shortens the QT interval and increases the densities of inward and delayed rectifier potassium currents in orchiectomized male rabbits. Cardiovasc. Res. $\mathbf{5 7}$ 28-36 (2003).

90. Verkerk, A. O. et al. Gender disparities in cardiac cellular electrophysiology and arrhythmia susceptibility in human failing ventricular myocytes. Int. Heart J. 46, 1105-1118 (2005).

91. Feiner, R. \& Dvir, T. Engineering smart hybrid tissues with built-in electronics. iScience 23, 100833 (2020).

92. Radisic, M. et al. Optical mapping of impulse propagation in engineered cardiac tissue. Tissue Eng. Part A 15, 851-860 (2009)

93. Yang, X. et al. Oestrogen upregulates L-type $\mathrm{Ca}^{2+}$ channels via oestrogen-receptor- $\alpha$ by a regional genomic mechanism in female rabbit hearts. J. Physiol. 590, 493-508 (2012).

94. Machuki, J. O. et al. Estrogen regulation of cardiac cAMP-L-type $\mathrm{Ca}^{2+}$ channel pathway modulates sex differences in basal contraction and responses to $\beta_{2} A R$-mediated stress in left ventricular apical myocytes. Cell Commun. Signal. 17, 34 (2019).

95. Parks, R. J., Ray, G., Bienvenu, L. A., Rose, R. A $\&$ Howlett, S. E. Sex differences in SR $\mathrm{Ca}^{2+}$ release in murine ventricular myocytes are regulated by the CAMP/PKA pathway. J. Mol. Cell. Cardiol. 75, 162-173 (2014)

96. Bell, J. R. et al. Male and female hypertrophic rat cardiac myocyte functional responses to ischemic stress and $\beta$-adrenergic challenge are different. Biol. Sex Differ. 7, 32 (2016).

97. Hoeker, G. S., Hood, A. R., Katra, R. P., Poelzing, S. $\varangle$ Pogwizd, S. M. Sex differences in $\beta$-adrenergic responsiveness of action potentials and intracellular calcium handling in isolated rabbit hearts. PLOS ONE 9, e111411 (2014).

98. Herron, T. J., Lee, P. \& Jalife, J. Optical imaging of voltage and calcium in cardiac cells $\&$ tissues. Circ. Res. 110, 609-623 (2012).

99. Cherry, E. M. \& Fenton, F. H. Visualization of spiral and scroll waves in simulated and experimental cardiac tissue. New J. Phys. 10, 125016 (2008)

100. Khalifa, A. R. M. et al. Sex-specific differences in mitochondria biogenesis, morphology, respiratory function, and ROS homeostasis in young mouse heart and brain. Physiol. Rep. 5, e13125 (2017).

101. Sbert-Roig, M. et al. GPER mediates the effects of $17 \beta$-estradiol in cardiac mitochondrial biogenesis and function. Mol. Cell. Endocrinol. 420, 116-124 (2016).

102. Rattanasopa, C., Phungphong, S., Wattanapermpool, J. $\&$ Bupha-Intr, T. Significant role of estrogen in maintaining cardiac mitochondrial functions. J. Steroid Biochem. Mol. Biol. 147, 1-9 (2015).

103. Pavón, N. et al. In female rat heart mitochondria oophorectomy results in loss of oxidative phosphorylation. J. Endocrinol. 232, 221-235 (2017).

104. Ribeiro Junior, R. F. et al. Estrogen regulates spatially distinct cardiac mitochondrial subpopulations. Mitochondrion 35, 87-96 (2017).

105. Chweih, H., Castilho, R. F. \& Figueira, T. R. Tissue and sex specificities in $\mathrm{Ca}^{2+}$ handling by isolated mitochondria in conditions avoiding the permeability transition. Exp. Physiol. 100, 1073-1092 (2015).

106. Milerová, M. et al. Sex difference in the sensitivity of cardiac mitochondrial permeability transition pore to calcium load. Mol. Cell. Biochem. 412, 147-154 (2016).

107. Ribeiro, R. F. et al. Sex differences in the regulation of spatially distinct cardiac mitochondrial subpopulations. Mol. Cell. Biochem. 419, 41-51 (2016).

108. Vijay, V. et al. Sexual dimorphism in the expression of mitochondria-related genes in rat heart at different ages. PLOS ONE 10, e0117047 (2015).

109. Norheim, F. et al. Gene-by-sex interactions in mitochondrial functions and cardio-metabolic traits. Cell Metab. 29, 932-949.e4 (2019).

110. Bhute, V. J et al. Metabolomics identifies metabolic markers of maturation in human pluripotent stem cell-derived cardiomyocytes. Theranostics 7 , 2078-2091 (2017)

111. Bekhite, M. M. et al. Longitudinal metabolic profiling of cardiomyocytes derived from human-induced pluripotent stem cells. Basic Res. Cardiol. 115, 37 (2020).

112. Ho, E., Karimi Galougahi, K., Liu, C.-C., Bhindi, R. \& Figtree, G. A. Biological markers of oxidative stress: applications to cardiovascular research and practice. Redox Biol. 1, 483-491 (2013).

113. Dedkova, E. N. \& Blatter, L. A. Measuring mitochondrial function in intact cardiac myocytes. J. Mol. Cell. Cardiol. 52, 48-61 (2012).
114. Li, Y.-C. E. \& Lee, I.-C. The current trends of biosensors in tissue engineering. Biosensors 10, 88 (2020).

115. Woodward, M. Cardiovascular disease and the female disadvantage. Int. J. Environ. Res. Public Health 16, 1165 (2019)

116. Stramba-Badiale, M. et al., Cardiovascular diseases in women: a statement from the policy conference of the European Society of Cardiology. European Heart J. 27, 994-1005 (2006)

117. Dedkov, E. I. et al. Sex-related differences in intrinsic myocardial properties influence cardiac function in middle-aged rats during infarction-induced left ventricular remodeling. Physiol. Rep. 4, e 12822 (2016).

118. Ostádal, B., Procházka, J., Pelouch, V., Urbanová, D. $\&$ Widimskȳ, J. Comparison of cardiopulmonary responses of male and female rats to intermittent high altitude hypoxia. Physiol. Bohemoslov. 33, 129-138 (1984).

119. Haddad, G. E. et al. Human cardiac-specific cDNA array for idiopathic dilated cardiomyopathy: sexrelated differences. Physiol. Genomics 33, 267-277 (2008).

120. Schuster, I. et al. Cardiomyocyte-specific overexpression of oestrogen receptor $\beta$ improves survival and cardiac function after myocardial infarction in female and male mice. Clin. Sci. 130 365-376 (2016)

121. Menazza, S. et al. Non-nuclear estrogen receptor alpha activation in endothelium reduces cardiac ischemia-reperfusion injury in mice. J. Mol. Cell. Cardiol. 107, 41-51 (2017)

122. Wang, M. et al. Mitochondrial connexin 43 in sex-dependent myocardial responses and estrogenmediated cardiac protection following acute ischemia reperfusion injury. Basic Res. Cardiol 115, 1 (2019).

123. Patten, R. D et al. 17 $\beta$-Estradiol reduces cardiomyocyte apoptosis in vivo and in vitro via activation of phospho-inositide-3 kinase/Akt signaling. Circ. Res. 95, 692-699 (2004).

124. Dunlay, S. M. \& Roger, V. L. Gender differences in the pathophysiology, clinical presentation, and outcomes of ischemic heart failure. Curr. Heart Fail. Rep. 9. 267-276 (2012)

125. Chen, T. \& Vunjak-Novakovic, G. Human tissue engineered model of myocardial ischemia-reperfusion injury. Tissue Eng. Part A 25, 711-724 (2018).

126. Kerkhof, P. L. M. Characterizing heart failure in the ventricular volume domain. Clin. Med. Insights Cardiol. 9, 11-31 (2015).

127. Kararigas, G. et al. Sex-dependent regulation of fibrosis and inflammation in human left ventricular remodelling under pressure overload. Eur. J. Heart Fail. 16, 1160-1167 (2014).

128. Regitz-Zagrosek, V. et al. Gender in cardiovascular diseases: impact on clinical manifestations, management, and outcomes. Eur. Heart J. 37, 24-34 (2016).

This comprehensive review covers sex-based and gender-based differences clinically observed in several notable cardiovascular diseases.

129. Nijenkamp, L. L. A. M. et al. Sex differences at the time of myectomy in hypertrophic cardiomyopathy. Circ. Heart Fail. 11, e004133 (2018)

130. Nijenkamp, L. L. A. M. et al. Sex-specific cardiac remodeling in early and advanced stages of hypertrophic cardiomyopathy. PLOS ONE 15 e0232427 (2020).

131. Peter, I. et al. Association of estrogen receptor $\beta$ gene polymorphisms with left ventricular mass and wall thickness in women. Am. J. Hypertens. 18 1388-1395 (2005).

132. Cocker, M. S., Abdel-Aty, H., Strohm, O. \& Friedrich, M. G. Age and gender effects on the extent of myocardial involvement in acute myocarditis a cardiovascular magnetic resonance study. Heart 95 1925-1930 (2009).

133. Deng, Q. et al. Suspected myocardial injury in patients with COVID-19: Evidence from front-line clinical observation in Wuhan, China. Int. J. Cardiol. 311 116-121 (2020)

134. Han, H. et al. Analysis of heart injury laboratory parameters in 273 COVID-19 patients in one hospital in Wuhan, China. J. Med. Virol. 92, 819-823 (2020).

135. Ghosh, S. \& Klein, R. S. Sex drives dimorphic immune responses to viral infections. J. Immunol. 198 1782-1790 (2017)

136. Channappanavar, R. et al. Sex-based differences in susceptibility to severe acute respiratory syndrome coronavirus infection. J. Immunol. 198, 4046-4053 (2017). 
137. Villa, A., Rizzi, N., Vegeto, E., Ciana, P. \& Maggi, A. Estrogen accelerates the resolution of inflammation in macrophagic cells. Sci. Rep. 5, 15224 (2015).

138. Khalid, N., Ahmad, S. A., Shlofmitz, E. \& Chhabra, L. Racial and gender disparities among patients with Takotsubo syndrome. Clin. Cardiol. 42, 19 (2018)

139. Khalid, N., Ahmad, S. A., Shlofmitz, E. \& Chhabra, L. Pathophysiology of Takotsubo Syndrome (StatPearls Publishing, 2021)

140. Cao, X. et al. Estrogen resisted stress-induced cardiomyopathy through increasing the activity of $\beta 2 A R-G a s$ signal pathway in female rats. Int. J. Cardiol. 187, 377-386 (2015).

141. James, A. F. \& Hancox, J. C. Sex, drugs and arrhythmia: are gender differences in risk of torsades de pointes simply a matter of testosterone? Cardiovascular Res. 57, 1-4 (2003).

142. Rudic, B., Schimpf, R. \& Borggrefe, M. Short QT syndrome - review of diagnosis and treatment. Arrhythm. Electrophysiol. Rev. 3, 76-79 (2014).

143. Soldin, O. P., Chung, S. H. \& Mattison, D. R. Sex differences in drug disposition. J. Biomed. Biotechnol. 2011, 187103 (2011)

144. Tamargo, J. et al. Gender differences in the effects of cardiovascular drugs. Eur. Heart J. Cardiovasc. Pharmacother. 3, 163-182 (2017).

This review discusses the influence of sex and gender on the pharmacokinetics and pharmacodynamics of cardiovascular drugs, and how they can create sex-specific differences in drug efficacy and safety.

145. Zucker, I. \& Prendergast, B. J. Sex differences in pharmacokinetics predict adverse drug reactions in women. Biol. Sex Differ. 11, 32 (2020).

146. Spoletini, I., Vitale, C., Malorni, W. \& Rosano, G. M. C. in Sex and Gender Differences in Pharmacology (ed. Regitz-Zagrosek, V.) 91-105 (Springer, 2012).

147. Krecic-Shepard, M. E., Barnas, C. R., Slimko, J. Jones, M. P. \& Schwartz, J. B. Gender-specific effects on verapamil pharmacokinetics and pharmacodynamics in humans. J. Clin. Pharmacol. 40, 219-230 (2000).

148. Murphy, E. \& Steenbergen, C. Sex, drugs, and trial design: sex influences the heart and drug responses. J. Clin. Invest. 124, 2375-2377 (2014).

149. Harvey, P. A. \& Leinwand, L. A. Oestrogen enhances cardiotoxicity induced by Sunitinib by regulation of drug transport and metabolism. Cardiovasc. Res. 107 66-77 (2015)

150. Takahashi, K. \& Yamanaka, S. Induction of pluripotent stem cells from mouse embryonic and adult fibroblast cultures by defined factors. Cell 126, 663-676 (2006)

151. Matsa, E. et al. Transcriptome profiling of patientspecific human iPSC-cardiomyocytes predicts individual drug safety and efficacy responses in vitro. Cell Stem Cell 19, 311-325 (2016).

152. Sun, N. et al. Patient-specific induced pluripotent stem cells as a model for familial dilated cardiomyopathy. Sci. Transl Med. 4, 130ra47 (2012).

153. Hinson, J. T. et al. Titin mutations in iPS cells define sarcomere insufficiency as a cause of dilated cardiomyopathy. Science 349, 982-986 (2015).

154. Stienen, S. et al. Sex differences in circulating proteins in heart failure with preserved ejection fraction. Biol. Sex Differ. 11, 47 (2020).

155. Lau, E. S. et al. Sex differences in circulating biomarkers of cardiovascular disease. J. Am. Coll. Cardiol. 74, 1543-1553 (2019).

156. Aguado, B. A. et al. Transcatheter aortic valve replacements alter circulating serum factors to mediate myofibroblast deactivation. Sci. Transl Med. 11 (2019).

Proteomics study on serum samples collected from male and female patients pre and post transcatheter aortic valve replacement, investigating the effect of serum treatment on valve and cardiac cells on hydrogels in vitro revealing sex-specific differences in cellular response.

157. Wagner, K. T., Nash, T. R., Liu, B., Vunjak-Novakovic, G. $\&$ Radisic, M. Extracellular vesicles in cardiac regeneration: potential applications for tissues-on-achip. Trends Biotechnol. 39, 755-773 (2021).

158. Liu, X. et al. U-shape suppressive effect of phenol red on the epileptiform burst activity via activation of estrogen receptors in primary hippocampal culture. PLOS ONE 8, e60189 (2013).

159. American Urological Association. Testosterone deficiency guideline. American Urological Association https://www.auanet.org/guidelines/testosteronedeficiency-guideline (2018)

160. Stanczyk, F. Z. \& Clarke, N. J. Measurement of estradiol-challenges ahead. J. Clin. Endocrinol. Metab. 99, 56-58 (2014).
161. Ferri, F. in Ferri's Clinical Advisor 2019 1st edn (Elsevier, 2018)

162. Tallawi, M. et al. Strategies for the chemical and biological functionalization of scaffolds for cardiac tissue engineering: a review. J. R. Soc. Interface 12 , 20150254 (2015).

163. Caballero Aguilar, L. M., Silva, S. M. \& Moulton, S. E. Growth factor delivery: Defining the next generation platforms for tissue engineering. J. Control. Release 306, 40-58 (2019).

164. Freeman, I. \& Cohen, S. The influence of the sequential delivery of angiogenic factors from affinity-binding alginate scaffolds on vascularization. Biomaterials 30, 2122-2131 (2009)

165. Garbern, J. C., Minami, E., Stayton, P. S. \& Murry, C. E. Delivery of basic fibroblast growth factor with a $\mathrm{pH}$-responsive, injectable hydrogel to improve angiogenesis in infarcted myocardium. Biomaterials 32, 2407-2416 (2011)

166. Sapir, Y., Ruvinov, E., Polyak, B. \& Cohen, S. in Cardiac Tissue Engineering: Methods and Protocols (eds Radisic, M. \& Black, L. D. III) 83-95 (Springer, 2014).

167. Azagarsamy, M. A. \& Anseth, K. S. Wavelengthcontrolled photocleavage for the orthogonal and sequential release of multiple proteins. Angew. Chem. Int. Ed. 125, 14048-14052 (2013).

168. Feiner, R. et al. A stretchable and flexible cardiac tissue-electronics hybrid enabling multiple drug release, sensing, and stimulation. Small 15, 1805526 (2019).

169. Bhatia, S. N. \& Ingber, D. E. Microfluidic organson-chips. Nat. Biotechnol. 32, 760-772 (2014).

170. Edington, C. D. et al. Interconnected microphysiological systems for quantitative biology and pharmacology studies. Sci. Rep. 8, 4530 (2018).

171. Xiao, S. et al. A microfluidic culture model of the human reproductive tract and 28-day menstrual cycle. Nat. Commun. 8, 14584 (2017).

This in vitro microfluidic platform supports murine ovarian follicles and produces the dynamic hormone profile of the human 28-day menstrual cycle, supporting and controlling human reproductive tract and peripheral tissue dynamics in an integrated platform for use in drug discovery and testing applications.

172. Park, S.-R et al. Development of a novel dual reproductive organ on a chip: recapitulating bidirectional endocrine crosstalk between the uterine endometrium and the ovary. Biofabrication 13 , 015001 (2020).

173. Sittadjody, S. et al. Engineered multilayer ovarian tissue that secretes sex steroids and peptide hormones in response to gonadotropins. Biomaterials 34, 2412-2420 (2013).

174. Hellström, M. et al. Bioengineered uterine tissue supports pregnancy in a rat model. Fertil. Steril. 106. 487-496.e1 (2016).

175. van Meer, B. J. et al. Small molecule absorption by PDMS in the context of drug response bioassays. Biochem. Biophys. Res. Commun. 482, 323-328 (2017).

176. Salama, G. \& Bett, G. C. L. Sex differences in the mechanisms underlying long QT syndrome. $\mathrm{Am}$. J. Physiol. Heart Circ. Physiol. 307, H640-H648 (2014)

177. Foryst-Ludwig, A. \& Kintscher, U. Sex differences in exercise-induced cardiac hypertrophy. Pflugers Arch. 465, 731-737 (2013).

178. Schoen, B. et al. Electrospun extracellular matrix: paving the way to tailor-made natural scaffolds for cardiac tissue regeneration. Adv. Funct. Mater. 27, 1700427 (2017).

179. Lutolf, M. P. \& Hubbell, J. A. Synthetic biomaterials as instructive extracellular microenvironments for morphogenesis in tissue engineering. Nat. Biotechnol. 23, 47-55 (2005)

180. Bassat, E. et al. The extracellular matrix protein agrin promotes heart regeneration in mice. Nature $\mathbf{5 4 7}$, 179-184 (2017).

181. Zhang, J., Zhu, W., Radisic, M. \& Vunjak-Novakovic, C. Can we engineer a human cardiac patch for therapy? Circ. Res. 123, 244-265 (2018)

182. Pati, F. et al. Printing three-dimensional tissue analogues with decellularized extracellular matrix bioink. Nat. Commun. 5, 3935 (2014)

183. Efraim, Y. et al. Biohybrid cardiac ECM-based hydrogels improve long term cardiac function post myocardial infarction. Acta Biomater. 50, 220-233 (2017).

184. Fleischer, S. et al. Albumin fiber scaffolds for engineering functional cardiac tissues. Biotechnol. Bioeng. 111, 1246-1257 (2014).
185. Ott, H. C. et al. Perfusion-decellularized matrix: using nature's platform to engineer a bioartificial heart. Nat. Med. 14, 213-221 (2008)

186. Godier-Furnémont, A. F. G. et al. Composite scaffold provides a cell delivery platform for cardiovascular repair. Proc. Natl Acad. Sci. USA 108, 7974-7979 (2011).

187. Diaz, M. D. et al. Injectable myocardial matrix hydrogel mitigates negative left ventricular remodeling in a chronic myocardial infarction model. Basic Transl Sci. 6, 350-361 (2021).

188. Engelmayr, G. C. et al. Accordion-like honeycombs for tissue engineering of cardiac anisotropy. Nat. Mater. 7, 1003-1010 (2008).

189. Fleischer, S. et al. Spring-like fibers for cardiac tissue engineering. Biomaterials 34, 8599-8606 (2013).

190. Aguado, B. A., Grim, J. C., Rosales, A. M., Watson-Capps, J. J. \& Anseth, K. S. Engineering precision biomaterials for personalized medicine Sci. Transl Med. 10, eaam8645 (2018).

191. Sun, W. et al. Engineering precision medicine. Adv. Sci. 6, 1801039 (2019).

192. James, B. D., Guerin, P. \& Allen, J. B. Let's talk about sex - biological sex is underreported in biomaterial studies. Adv. Healthc. Mater. 10, e2001034 (2021).

193. Pomeroy, J. E., Helfer, A. \& Bursac, N. Biomaterializing the promise of cardiac tissue engineering. Biotechnol. Adv. 42, 107353 (2020).

194. Singelyn, J. M. et al. Naturally derived myocardial matrix as an injectable scaffold for cardiac tissue engineering. Biomaterials 30, 5409-5416 (2009).

195. O'Neill, J. D. et al. Decellularization of human and porcine lung tissues for pulmonary tissue engineering. Ann. Thorac. Surg. 96, 1046-1056 (2013).

196. Shimoda, H. et al. Decellularized liver scaffolds promote liver regeneration after partial hepatectomy. Sci. Rep. 9, 12543 (2019).

197. Stewart, J A Cashatt, D. O Borck, A. C. Brown, J. E. \& Carver, W. E. 17 $\beta$-estradiol modulation of angiotensin II-stimulated response in cardiac fibroblasts. J. Mol. Cell. Cardiol. 41, 97-107 (2006).

198. Pedram, A., Razandi, M., Narayanan, R. \& Levin, E. R. Estrogen receptor beta signals to inhibition of cardiac fibrosis. Mol. Cell. Endocrinol. 434, 57-68 (2016).

199. Yasui, H. et al. Excitation propagation in threedimensional engineered hearts using decellularized extracellular matrix. Biomaterials 35, 7839-7850 (2014).

200. Hodgson, M. J., Knutson, C. C., Momtahan, N. \& Cook, A. D. Extracellular matrix from whole porcine heart decellularization for cardiac tissue engineering. Methods Mol. Biol. 1577, 95-102 (2018).

201. Bridgman, P. et al. Gender-specific patterns of left ventricular and myocyte remodeling following myocardial infarction in mice deficient in the angiotensin II type 1 a receptor. Am. J. Physiol. Heart Circ. Physiol. 289, H586-H592 (2005)

202. Tastet, L. et al. Sex-related differences in the extent of myocardial fibrosis in patients with aortic valve stenosis JACC Cardiovasc. Imaging 13, 699-711 (2020).

203. Mannhardt, I. et al. Comparison of 10 control hPSC lines for drug screening in an engineered heart tissue format. Stem Cell Rep. 15, 983-998 (2020).

204. Harman, S. M. et al. Timing and duration of menopausal hormone treatment may affect cardiovascular outcomes. Am. J. Med. 124, 199-205 (2011).

205. Tomov, M. L. et al. Engineering functional cardiac tissues for regenerative medicine applications. Curr. Cardiol. Rep. 21, 105 (2019).

206. Doppler, S. A. et al. Mammalian heart regeneration the race to the finish line. Circ. Res. 120, 630-632 (2017).

207. Rodrigues, I. C. P., Kaasi, A., Maciel, R., Jardini, A. L. $\&$ Gabriel, L. P. Cardiac tissue engineering: current state-of-the-art materials, cells and tissue formation. Einstein 16, eRB4538 (2018).

208. Reed, R. M. et al. Cardiac size and sex matching in heart transplantation. JACC Heart Fail. 2, 73-83 (2014).

209. Martinez-Selles, M. et al. Donor/recipient sex mismatch and survival after heart transplantation: only an issue in male recipients? An analysis of the Spanish Heart Transplantation Registry. Transpl. Int 28, 305-313 (2015)

210. Bergenfeldt, H., Stehlik, J., Höglund, P., Andersson, B. $\&$ Nilsson, J. Donor-recipient size matching and mortality in heart transplantation: Influence of body mass index and gender. J. Heart Lung Transpl. 36, 940-947 (2017).

211. Weiss, E. S. et al. The impact of donor-recipient sex matching on survival after orthotopic heart 
transplantation: analysis of 18000 transplants in the modern era Circ. Heart Fail. 2, 401-408 (2009).

212. Khush, K. K., Kubo, J. T. \& Desai, M. Influence of donor and recipient sex mismatch on heart transplant outcomes: analysis of the International Society for Heart and Lung Transplantation Registry. J. Heart Lung Transpl. 31, 459-466 (2012).

213. Boese, A. C., Kim, S. C., Yin, K.-J., Lee, J.-P. \& Hamblin, M. H. Sex differences in vascular physiology and pathophysiology: estrogen and androgen signaling in health and disease. Am. J. Physiol. Heart Circ. Physiol. 313, H524-H545 (2017).

This review discusses sex-based differences in vascular physiology and pathophysiology, specifically covering the roles and effects of oestrogen and androgen receptor signalling in the pathophysiology of different vascular diseases.

214. White, M. C. Fleeman, R. \& Arnold A C. Sex differences in the metabolic effects of the reninangiotensin system. Biol. Sex Differ. 10, 31 (2019).

215. Ghazi, L. \& Drawz, P. Advances in understanding the renin-angiotensin-aldosterone system (RAAS) in blood pressure control and recent pivotal trials of RAAS blockade in heart failure and diabetic nephropathy. F1000Research 6, 297 (2017).

216. Toering, T. J. et al. Sex differences in renin-angiotensinaldosterone system affect extracellular volume in healthy subjects. Am. J. Physiol. Ren. Physiol. 314, F873-F878 (2017)

217. Huxley, V. H. \& Kemp, S. S. Sex-specific characteristics of the microcirculation. Adv. Exp. Med. Biol. 1065 307-328 (2018)

218. Sabbatini, A. R. \& Kararigas, G. Menopause-related estrogen decrease and the pathogenesis of HFpEF: JACC review topic of the week. J. Am. Coll. Cardiol. 75, 1074-1082 (2020)

219. Oliva, M. et al. The impact of sex on gene expression across human tissues. Science 369, eaba3066 (2020). This study examined data from the GenotypeTissue Expression (GTEx) project in a sex-specific manner, uncovering genome-wide instances of tissue-specific, sex-biased gene expression, as well as sex-specific differences in cell composition.

220. Schepers, A., Li, C., Chhabra, A., Seney, B. T. \& Bhatia, S. Engineering a perfusable 3D human liver platform from iPS cells. Lab Chip 16, 2644-2653 (2016).

221. Huh, D. et al. Reconstituting organ-level lung functions on a chip. Science 328, 1662-1668 (2010).

222. Musah, S. et al. Mature induced-pluripotent-stem-cellderived human podocytes reconstitute kidney glomerular-capillary-wall function on a chip. Nat. Biomed. Eng. 1, 0069 (2017).

223. Mansour, A. A. et al. An in vivo model of functional and vascularized human brain organoids. Nat. Biotechnol. 36, 432-441 (2018).

224. Fleischer, S., Tavakol, D. N. \& Vunjak-Novakovic, C. From arteries to capillaries: approaches to engineering human vasculature. Adv. Funct. Mater. 30, 1910811 (2020).

225. Mithal, A. et al. Generation of mesenchyme free intestinal organoids from human induced pluripotent stem cells Nat Commun 11, 215 (2020).

226. Sabbatini, A. R. \& Kararigas, G. Estrogen-related mechanisms in sex differences of hypertension and target organ damage. Biol. Sex Differ. 11, 31 (2020).

227. Komukai, K., Mochizuki, S. \& Yoshimura, M. Gender and the renin-angiotensin-aldosterone system. Fundam. Clin. Pharmacol. 24, 687-698 (2010)

228. Kalibala, J. \& Pech, A. Gender differences in cardiovascular pharmacotherapy - the example of hypertension: a mini review. Front. Pharmacol. 11, 8 (2020).

229. Keller, K. M. \& Howlett, S. E. Sex differences in the biology and pathology of the aging heart. Can. J. Cardiol. 32, 1065-1073 (2016).

230. Ramaekers, D., Ector, H., Aubert, A. E., Rubens, A $\Sigma$ Van de Werf, F. Heart rate variability and heart rate in healthy volunteers. Is the female autonomic nervous system cardioprotective? Eur. Heart J. 19, 1334-1341 (1998)

231. Murphy, E., Amanakis, G., Fillmore, N., Parks, R. J. \& Sun, J. Sex differences in metabolic cardiomyopathy. Cardiovasc. Res. 113, 370-377 (2017)

232. Papadopoulou, S. A. \& Kaski, J. C. Ischaemic heart disease in the ageing woman. Best Pract. Res. Clin. Obstet. Gynaecol. 27, 689-697 (2013).

233. Mehta, L. S. et al. Acute myocardial infarction in women. Circulation 133, 916-947 (2016).

234. Lam, C. S. P. et al. Sex differences in heart failure. Eur. Heart J. 40, 3859-3868c (2019).
235. Azad, N., Kathiravelu, A., Minoosepeher, S., Hebert, P. $\&$ Fergusson, D. Gender differences in the etiology of heart failure: a systematic review. J. Geriatr. Cardiol. 8, 15-23 (2011)

236. Savarese, G. \& D'Amario, D. in Sex-Specific Analysis of Cardiovascular Function Vol. 1065 (eds. Kerkhof, P. L. M. \& Miller, V. M.) 529-544 (Springer, 2018)

237. Dewan, $P$ et al Sex-related differences in heart failure with preserved ejection fraction. Circ. Heart Fail. 12, e006539 (2019)

238. Kubo, T. et al. Gender-specific differences in the clinical features of hypertrophic cardiomyopathy in a community-based Japanese population: results from Kochi RYOMA study. J. Cardiol. 56, 314-319 (2010).

239. Siontis, K. C., Ommen, S. R. \& Geske, J. B. Sex, survival, and cardiomyopathy: differences between men and women with hypertrophic cardiomyopathy. J. Am. Heart Assoc. 8, e014448 (2019).

240. van Driel, B., Nijenkamp, L., Huurman, R., Michels, M. $\&$ van der Velden, J. Sex differences in hypertrophic cardiomyopathy: new insights. Curr. Opin. Cardiol. 34 254-259 (2019)

241. Fairweather, D., Cooper, L. T. \& Blauwet, L. A. Sex and gender differences in myocarditis and dilated cardiomyopathy. Curr. Probl. Cardiol. 38, 7-46 (2013).

242. De Maria, R. et al. Comparison of clinical findings in idiopathic dilated cardiomyopathy in women versus men. The Italian Multicenter Cardiomyopathy Study Group (SPIC). Am. J. Cardiol. 72, 580-585 (1993)

243. Cannatà, A. et al. Sex differences in the long-term prognosis of dilated cardiomyopathy. Can. J. Cardiol. 36, 37-44 (2020)

244. Halliday, B. P. et al. Sex- and age-based differences in the natural history and outcome of dilated cardiomyopathy. Eur. J. Heart Fail. 20, 1392-1400 (2018).

245. Felker, G. M. et al. The spectrum of dilated cardiomyopathy: the Johns Hopkins experience with 1,278 patients. Medicine 78, 270-283 (1999).

246. Kyto, V., Sipila, J. \& Rautava, P. Gender differences in myocarditis: A nationwide study in Finland. Eur. Heart J. 34, 3505 (2013).

247. Murakami, T. et al. Gender differences in patients with takotsubo cardiomyopathy: multi-center registry from Tokyo CCU Network. PLoS ONE 10, 0136655 (2015).

248. Kim, H. Y. et al. Gender differences in clinical profiles of stress-induced cardiomyopathy. $J$. Cardiovasc. Ultrasound 25, 111-117 (2017).

249. Agdamag, A. C. et al. Sex differences in takotsubo syndrome: a narrative review. J. Womens Health 29 1122-1130 (2019).

250. Conrath, C. E. et al. Gender differences in the long QT syndrome: effects of $\beta$-adrenoceptor blockade. Cardiovasc. Res. 53, 770-776 (2002).

251. Lehmann, M. H. et al. Age-gender influence on the rate-corrected QT interval and the OT-heart rate relation in families with genotypically characterized long OT syndrome. J. Am. Coll. Cardiol. 29, 93-99 (1997).

252. Cashman, T. J., Josowitz, R., Johnson, B. V., Gelb, B. D. $\&$ Costa, K. D. Human engineered cardiac tissues created using induced pluripotent stem cells reveal functional characteristics of BRAF-mediated hypertrophic cardiomyopathy. PLOS ONE 11 e0146697 (2016)

253. Wang, G. et al. Modeling the mitochondrial cardiomyopathy of Barth syndrome with induced pluripotent stem cell and heart-on-chip technologies. Nat. Med. 20, 616-623 (2014)

254. Hirt, M. N. et al. Increased afterload induces pathological cardiac hypertrophy: a new in vitro model. Basic Res. Cardiol. 107, 307 (2012).

255. Turnbull, I. C. et al. in Experimental Models of Cardiovascular Diseases: Methods and Protocols (ed. Ishikawa, K.) 145-159 (Springer, 2018)

256. Mastikhina, O. et al. Human cardiac fibrosis-on-a-chip model recapitulates disease hallmarks and can serve as a platform for drug testing. Biomaterials 233 119741 (2020).

257. Wang, E. Y. et al. Biowire model of interstitial and foca cardiac fibrosis. ACS Cent. Sci. 5, 1146-1158 (2019).

258. Kawatou, M. et al. Modelling torsade de pointes arrhythmias in vitro in 3D human iPS cell-engineered heart tissue. Nat. Commun. 8, 1078 (2017).

259. Nunes, S. S. et al. Human stem cell-derived cardiac model of chronic drug exposure. ACS Biomater. Sci. Eng. 3, 1911-1921 (2017).

260. Raznahan, A. et al. Sex-chromosome dosage effects on gene expression in humans. Proc. Natl Acad. SCi. USA 115, 7398-7403 (2018).

261. Kassam, I., Wu, Y., Yang, J., Visscher, P. M. $\delta$ McRae, A. F. Tissue-specific sex differences in human gene expression. Hum Mol. Genet. 28, 2976-2986 (2019).

262. Tukiainen, T. et al. Landscape of $X$ chromosome inactivation across human tissues. Nature $\mathbf{5 5 0}$ 244-248 (2017)

263. Carrel, L. \& Willard, H. F. X-inactivation profile reveals extensive variability in $\mathrm{X}$-linked gene expression in females. Nature 434, 400-404 (2005).

264. Godfrey, A. K. et al. Quantitative analysis of Y-chromosome gene expression across 36 human tissues. Genome Res. 30, 860-873 (2020).

265. Fang, H., Disteche, C. M. \& Berletch, J. B. X inactivation and escape: epigenetic and structural features. Front. Cell Dev. Biol. 7, 219 (2019).

266. Alegría-Torres, J. A., Baccarelli, A. \& Bollati, V. Epigenetics and lifestyle. Epigenomics 3, 267-277 (2011).

267. Hartman, R. J. G., Huisman, S. E. \& den Ruijter, H. M Sex differences in cardiovascular epigenetics - a systematic review. Biol. Sex Differ. 9, 19 (2018).

268. Fischer, K. E. \& Riddle, N. C. Sex differences in aging: genomic instability. J. Gerontol. Ser. A 73, 166-174 (2018).

269. Sierra, M. I., Fernăndez, A. F. \& Fraga, M. F. Epigenetics of aging. Curr. Genomics 16, 435-440 (2015).

270. Hines, M., Constantinescu, M. \& Spencer, D. Early androgen exposure and human gender development. Biol. Sex Differ. 6, 3 (2015)

271. Hall, J. E. Endocrinology of the menopause Endocrinol. Metab. Clin. North Am. 44, 485-496 (2015).

272. Kuciene, R. \& Dulskiene, V. Selected environmental risk factors and congenital heart defects. Medicina 44 827-832 (2008).

273. Dipietro, J. A. \& Voegtline, K. M. The gestational foundation of sex differences in development and vulnerability. Neuroscience 342, 4-20 (2017)

274. Mauvais-Jarvis, F. et al. Sex and gender: modifiers of health, disease, and medicine. Lancet 396, 565-582 (2020).

275. Varì, R. et al. Gender-related differences in lifestyle may affect health status. Ann. Ist. Super. Sanita $\mathbf{5 2}$ 158-166 (2016)

276. Rogers, R. G., Everett, B. G., Saint Onge, J. M. \& Krueger, P. M. Social, behavioral, and biological factors, and sex differences in mortality. Demography 47, 555-578 (2010)

277. Olalekan, S. A., Burdette, J. E., Getsios, S. Woodruff, T. K. \& Kim, J. J. Development of a novel human recellularized endometrium that responds to a 28-day hormone treatment. Biol. Reprod. 96 971-981 (2017)

278. Cook, C. D. et al. Local remodeling of synthetic extracellular matrix microenvironments by co-cultured endometrial epithelial and stromal cells enables longterm dynamic physiological function. Integr. Biol. 9, 271-289 (2017)

\section{Acknowledgements}

The authors gratefully acknowledge the funding support of their cardiac research by NIH (HL076485, EB025765, EB027062), NSF (grant NSF16478) and NASA (NNX16AO69A). All figures were created using BioRender.com.

\section{Author contributions}

R.L., H.A.A., S.F., M.T., Y.Z., M.R. and G.V.-N. conceptualized the manuscript R.L. H.A.A. S.F. M.T and YZ surveyed relevant literature and wrote the manuscript. M.R. and G.V.-N. edited and finalized the manuscript.

\section{Competing interests}

G.V.N and M.R are co-founders and shareholders of TARA Biosystems Inc. They serve on the Board of Directors and receive compensation for this role. Y.Z. and M.R. are inventors of a patent application on the Biowire II platform related to this work (US patent US20160282338A1), which has been licensed to TARA Biosystems Inc. G.V-N is inventor on a patent application on engineering adult-like human heart tissue (application no. 15/151,751). All other authors declare no competing interests.

\section{Peer review information}

Nature Reviews Materials thanks Brian Aguado, Christian Delles and Tal Dvir for their contribution to the peer review of this work.

\section{Publisher's note}

Springer Nature remains neutral with regard to jurisdictional claims in published maps and institutional affiliations.

C) Springer Nature Limited 2021 